\title{
Development of human somatosensory cortical functions - what have we learned from magnetoencephalography: a review
}

\author{
Päivi Nevalainen ${ }^{1,2}$ *, Leena Lauronen ${ }^{1,2}$ and Elina Pihko ${ }^{3}$ \\ BioMag Laboratory, Hospital District of Helsinki and Uusimaa, HUS Medical Imaging Center, Helsinki University Central Hospital, University of Helsinki, Helsinki, \\ Finland \\ ${ }^{2}$ Department of Clinical Neurophysiology, Children's Hospital, HUS Medical Imaging Center, Helsinki University Central Hospital, University of Helsinki, Helsinki, \\ Finland \\ ${ }^{3}$ Brain Research Unit, O.V. Lounasmaa Laboratory, Aalto University School of Science, Espoo, Finland
}

\section{Edited by:}

Hubert Preissl, University of Tübingen, Germany

Reviewed by:

Douglas Owen Cheyne, The Hospital for Sick Children, Canada

Margot J. Taylor, The Hospital for Sick

Children, Canada

*Correspondence:

Päivi Nevalainen, BioMag Laboratory, Hospital District of Helsinki and Uusimaa, HUS Medical Imaging Center, Helsinki University Central Hospital, P.O. Box 340, Helsinki

FIN-00029 HUS, Finland

e-mail:paivi.nevalainen@helsinki.fi
The mysteries of early development of cortical processing in humans have started to unravel with the help of new non-invasive brain research tools like multichannel magnetoencephalography (MEG). In this review, we evaluate, within a wider neuroscientific and clinical context, the value of MEG in studying normal and disturbed functional development of the human somatosensory system. The combination of excellent temporal resolution and good localization accuracy provided by MEG has, in the case of somatosensory studies, enabled the differentiation of activation patterns from the newborn's primary (SI) and secondary somatosensory (SII) areas. Furthermore, MEG has shown that the functioning of both SI and SII in newborns has particular immature features in comparison with adults. In extremely preterm infants, the neonatal MEG response from SII also seems to potentially predict developmental outcome: those lacking SII responses at term show worse motor performance at age 2 years than those with normal SII responses at term. In older children with unilateral early brain lesions, bilateral alterations in somatosensory cortical activation detected in MEG imply that the impact of a localized insult may have an unexpectedly wide effect on cortical somatosensory networks. The achievements over the last decade show that MEG provides a unique approach for studying the development of the somatosensory system and its disturbances in childhood. MEG well complements other neuroimaging methods in studies of cortical processes in the developing brain.

Keywords: magnetoencephalography, newborn, brain development, somatosensory system, preterm infant cerebral palsy

\section{INTRODUCTION}

Around the time of full-term birth, the central nervous system (CNS) of a human newborn is developing dramatically (Figure 1). Transient fetal brain structures, such as the subplate zone, are resolving (Kostovic and Rakic, 1990; De Graaf-Peters and HaddersAlgra, 2006) and neurotransmitter systems are undergoing marked changes (Ben-Ari et al., 2004; Herlenius and Lagercrantz, 2004; Dzhala et al., 2005). The active phase in dendritic development and synaptogenesis continues for months to years after birth (Huttenlocher and Dabholkar, 1997), whereas myelination, axonal withdrawal, and synapse elimination may continue up to the third decade of life (Huttenlocher and Dabholkar, 1997). (For a review on the ontogeny of the human CNS, see De Graaf-Peters and Hadders-Algra, 2006.) Considering all of these ongoing changes, early infancy is a very exiting period to investigate the building of neural networks and their functional development.

In recent years, several non-invasive brain research methods have been introduced for in vivo studies of the developing CNS. Advanced magnetic resonance imaging (MRI) techniques [such as voxel-based morphometry and diffusion tensor imaging (DTI)] allow not only the visualization but also the quantification of gray and white matter structures (e.g., Mathur et al., 2010). Furthermore, functional MRI (fMRI) detects hemodynamic changes related to neural activation providing spatially accurate information about brain activation in response to a stimulus (for a review, see e.g., Seghier and Hüppi, 2010) or about the so called resting-state networks (for a review, see e.g., Smyser et al., 2011). Of the available neurophysiological methods, electroencephalography (EEG) and evoked potentials have a long history in studies of all age groups. Magnetoencephalography (MEG), on the other hand, has been used in studies of newborns and infants only relatively recently (for a review, see e.g., Huotilainen, 2006; Lauronen et al., 2011). All of these brain research methodologies have their pros and cons, and combining the results obtained with different methods provides a comprehensive picture of brain development. This review discusses the discoveries made with MEG concerning normal and abnormal development of the human somatosensory system in infancy and childhood.

Magnetoencephalography detects the weak extracranial magnetic fields produced by synchronous activity of tens of thousands of cortical pyramidal neurons. More specifically, the MEG 


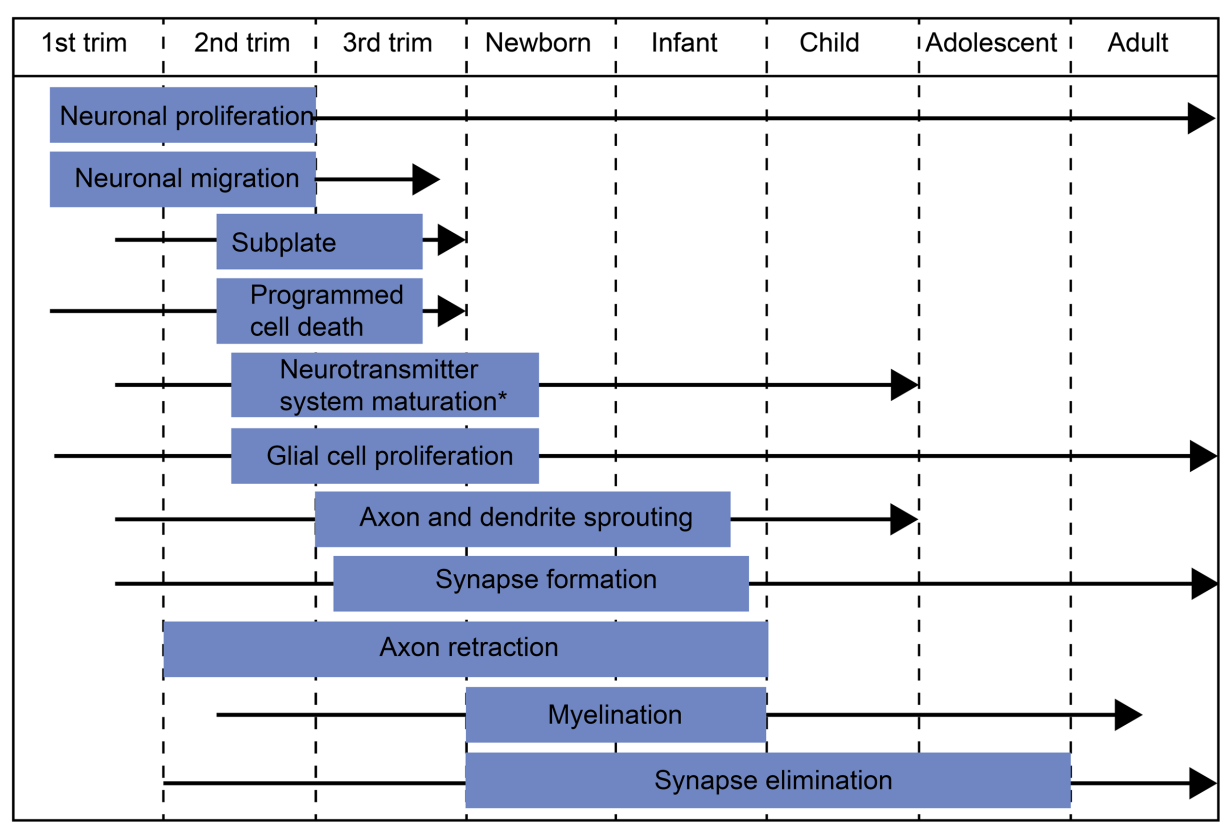

FIGURE 1 | Schematic diagram of major developmental events during embryonic/fetal life and infancy/early childhood. The blue box indicates the most active period of each developmental process and the black arrow the period when the process continues at a slower pace. * The most active period in neurotransmitter system maturation in general. The exact timescales of maturation for different neurotransmitter systems may differ from the indicated period. signal is thought to reflect synaptically induced intracellular currents flowing in the apical dendrites of cortical pyramidal cells (Hämäläinen et al., 1993). Thus, similar to EEG, the temporal resolution of MEG is in the millisecond range. In the spatial domain, source localization is simpler for MEG than EEG data due to the inherently different properties of the two methods: MEG is less sensitive to conductivity differences between the measuring device and the active brain source, and MEG preferentially detects sources oriented tangentially to the skull surface, whereas EEG detects both radial and tangential sources (Hämäläinen et al., 1993). Consequently, with MEG, brain processes can be studied relatively accurately both in time and space.

Somatosensory responses can be evoked by electrical stimulation of a peripheral nerve (e.g., median nerve) or by tactile stimulation of the skin (e.g., on the digits). Stimulation of the median nerve at the wrist activates a mixture of afferent and efferent fibers, including those innervating many types of cutaneous receptors in about two thirds of the palmar side of the hand. In most of the experiments reviewed here, the tactile stimulation was provided with an inflatable plastic diaphragm driven with pulses of compressed air. Such a stimulus feels like a gentle tap on the fingertip and activates mainly slowly adapting mechanoreceptors in a relatively localized skin area. Compared with median nerve stimulation, the early somatosensory evoked field (SEF) deflections to tactile stimulation have usually lower response amplitudes, and slightly longer latencies (Figure 2), partly due to the more distal stimulation site (e.g., wrist vs. fingertip). Nevertheless, in adults, the early cortical SEFs to both median nerve ( $\left.\mathrm{SEF}_{\mathrm{MN}}\right)$ and tactile stimulation $\left(\mathrm{SEF}_{\mathrm{T}}\right)$ consist of an initial deflection with an underlying current source pointing anteriorly (though this deflection is often minute after tactile stimulation, Figure $2, \mathrm{SEF}_{\mathrm{MN}} 20$ and $\mathrm{SEF}_{\mathrm{T}} 30^{1}$ ), and a subsequent deflection with current pointing posteriorly (Figure 2, $\mathrm{SEF}_{\mathrm{MN}} 35$ and $\mathrm{SEF}_{\mathrm{T}} 50$ ). The following sections discuss how and when such somatosensory response patterns are attained in infancy and what kind of underlying processes this development might reflect.

\section{NORMAL DEVELOPMENT OF THE SOMATOSENSORY SYSTEM}

In the following sections, we first review different aspects of somatosensory development and then discuss the relevant findings of developmental somatosensory MEG studies.

\section{FROM THE PERIPHERY TO THE PRIMARY SOMATOSENSORY AREAS}

Postmortem studies in human infants have shown that in the primary somatosensory areas, thalamic axons grow through

${ }^{1}$ The nomenclature used in the SEF and SEP literature for the different response components is variable and easily confusing. It is based on a long tradition of SEP studies, where the components are named according to their latency and the direction of the potential difference in an electrode, e.g., N20 for a deflection at $20 \mathrm{~ms}$ with a negative value with respect to a reference electrode. SEFs are often named accordingly, e.g., N20m, with the $m$ referring to "magnetic." The nomenclature gets even more confusing with different stimulation methods and in recordings of infants/children, where latencies (and hence nomenclature) deviate from those of adults. For clarity, in this review, we will use SEF/SEP $\mathrm{MN}$ and SEF/SEP $\mathrm{T}$ for adult responses to median nerve and tactile stimuli, respectively, and sef/sep $\mathrm{pN}_{\mathrm{MN}}$ and sef/sep $\mathrm{p}_{\mathrm{T}}$ for the respective responses of children. The number following the abbreviation of a response component refers to the latency of each response; e.g., $\mathrm{SEF}_{\mathrm{MN}} 20$ indicates adult SEF to median nerve stimulation peaking at $20 \mathrm{~ms}$. 

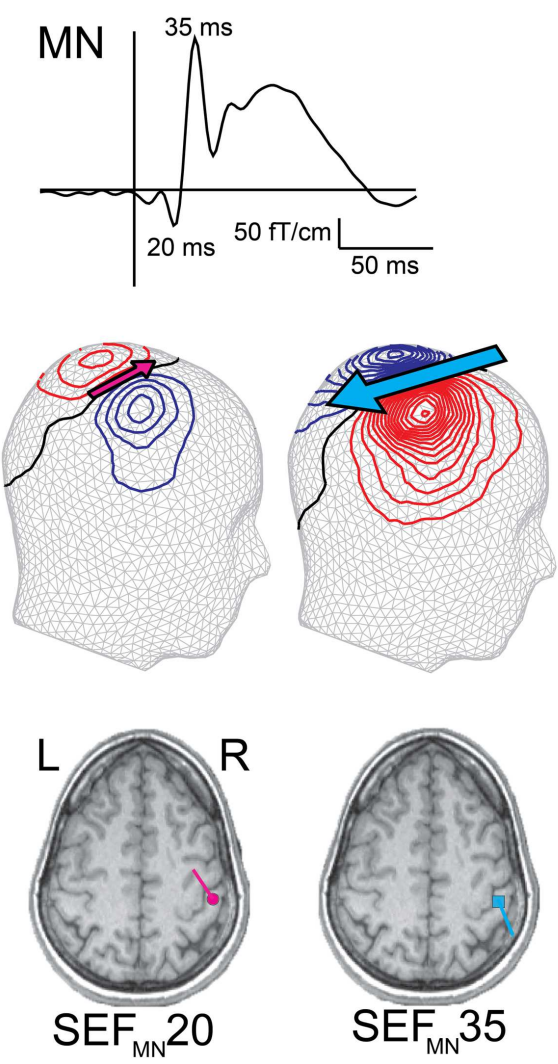

FIGURE 2 | Early adult SEFs to median nerve $\left(\mathrm{SEF}_{\mathrm{MN}}\right)$ and tactile $\left(\mathrm{SEF}_{\mathrm{T}}\right)$ stimulation. The SEF waveform from one gradiometer channel shows $\mathrm{SEF}_{\mathrm{MN}} 20 / \mathrm{SEF}_{\mathrm{T}} 30$ and $\mathrm{SEF}_{\mathrm{MN}} 35 / \mathrm{SEF}_{\mathrm{T}} 50$ deflections, and the magnetic contours - reflected on a head surface - reveal the different current orientations (indicated by the pink and blue arrows). Compared with $\mathrm{SEF}_{\mathrm{MN}}$, the $\mathrm{SEF}_{\mathrm{T}}$ latencies are slightly longer and amplitudes lower

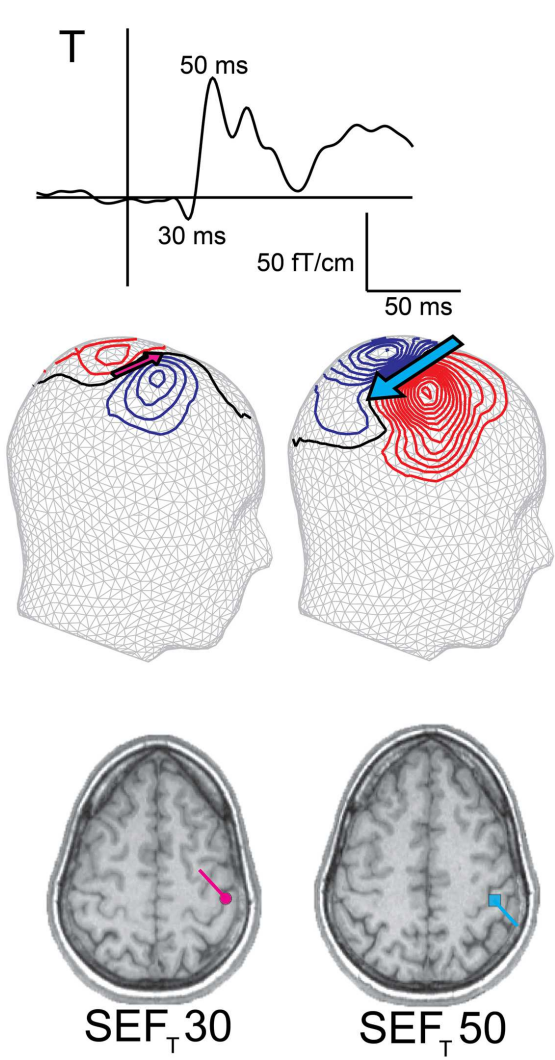

(note the different amplitude scales). Both stimulation methods, however, elicit an initial anteriorly pointing dipolar source,

$\mathrm{SEF}_{\mathrm{MN}} 20 / \mathrm{SEF}_{\mathrm{T}} 30$ (though in some subjects this deflection is minute to tactile stimulation), followed by a posteriorly pointing dipolar source, $\mathrm{SEF}_{\mathrm{MN}} 35 / \mathrm{SEF}_{\mathrm{T}} 50$. The dipoles are superimposed on individual MRIs and both sources are localized in $\mathrm{SI}$. the subplate, a transient fetal structure underneath the cortical plate, between the 17 and 26th gestational weeks $\left(\mathrm{GW}^{2}\right)$ (Kostovic and Rakic, 1990; Kostovic et al., 1995). During the early preterm period (26th-34th GW), these axons grow to the cortical plate and form the first thalamo-cortical connections, constituting the anatomical pathway for sensory impulses from the periphery to the cortex. Myelination starts in the human telencephalon around the 14th GW (Zecevic et al., 1998). In the pre- and post-central gyri, myelin is detectable around the 35th GW (Iai et al., 1997). Myelination then proceeds actively during the first postnatal year (Brody et al., 1987) and continues at a slower pace thereafter. In accordance with changes caused by pre-myelination and myelination, in vivo DTI data show a basic pattern of white matter maturation both before and after term-age. As a function of gestational age, mean diffusivity decreases and fractional anisotropy (a

${ }^{2}$ Gestational weeks (GW), used in clinical practice to describe the length of pregnancy and fetus age, are traditionally calculated from the first day of the last menstruation (approximately 2 weeks before conception), but presently determined by ultrasound scans during pregnancy. For uniformity, we will use gestational weeks (rather than conceptional weeks calculated from the day of conception) throughout this review. measure of relative degree of directionality of diffusion in a voxel) increases in a posterior-to-anterior and a central-to-peripheral order (Hüppi et al., 1998a; Berman et al., 2005; Yoshida et al., 2013).

In human infants, the functionality of the early connections from the periphery through thalamus to the primary somatosensory cortex (SI) can be explored in vivo with somatosensory evoked potentials (SEPs) recorded on the scalp, or with SEFs recorded extracranially with MEG. In preterm infants, median nerve SEPs are recordable on the scalp already by the 25 th GW (Hrbek et al., 1973). In the youngest preterm infants (<30 GW), the most striking feature of the scalp SEP is a large negative wave with a mean duration of $1500 \mathrm{~ms}$ (Hrbek et al., 1973; Vanhatalo et al., 2009). This slow wave can be detected without averaging when a tactile stimulus is given between bursts of the tracé discontinue EEG pattern of preterm infants (Milh et al., 2007; Vanhatalo et al., 2009). A concerted action of the subplate and cortex may be required for generation of this component (Kanold, 2009; Vanhatalo et al., 2009). With increasing gestational age, the amplitude of this slow wave gradually decreases and an earlier component, usually referred to as $\mathrm{N} 1$ in the literature, becomes detectable with a latency of approximately $90 \mathrm{~ms}$ somewhere between the 27 th 
(Taylor et al., 1996) and 29th GW (Hrbek et al., 1973). Toward term-age, the N1 latency rapidly decreases (Hrbek et al., 1973; Klimach and Cooke, 1988a; Karniski et al., 1992; Taylor et al., 1996; Smit et al., 2000), reaching approximately $30 \mathrm{~ms}$ at term-age ( sep $_{\mathrm{MN}} 30$ ), though with considerable inter-individual variability (Desmedt and Manil, 1970; Hrbek et al., 1973; Laget et al., 1976; Zhu et al., 1987; Laureau et al., 1988; Laureau and Marlot, 1990; George and Taylor, 1991; Gibson et al., 1992; Karniski, 1992).

In term-age infants, primary somatosensory responses have also been studied with MEG. In accordance with the neonatal $\operatorname{sep}_{M N} 30$, the initial SEF to median nerve stimulation in fullterm newborns peaks at around $30 \mathrm{~ms}\left(\operatorname{sef}_{\mathrm{MN}} 30\right)$. The MEG data together with earlier EEG findings suggest that this earliest cortical response in newborns reflects activation of a similar cortical ensemble as the earliest $\mathrm{SEF}_{\mathrm{MN}}$ response in adults $\left(\mathrm{SEF}_{\mathrm{MN}} 20\right.$ peaking at $20 \mathrm{~ms}$ ) (Lauronen et al., 2006) - that is, summated intracellular currents in cortical pyramidal cells in SI, specifically area $3 \mathrm{~b}$ in the anterior wall of postcentral gyrus (Allison et al., 1989a). Since the current direction in SI pyramidal cells during this early response is oriented from deeper to more superficial cortical layers, MEG source modeling yields an anteriorly pointing current dipole, which in SEP is recorded as a posterior negativity ( $\mathrm{SEP}_{\mathrm{MN}} 20$ in adults and sep $\mathrm{MN} 30$ in infants).

The development of this early response during childhood is primarily reflected in its latency (Figure 3). Although the absolute latencies differ between studies (due to, e.g., different stimulation method, filter settings, vigilance state/anesthesia), the general rule is that until the age of approximately 3-5 years, the sep $\mathrm{MN}_{\mathrm{N}} 30$ and $\operatorname{sef}_{\mathrm{T}} 30$ latency decreases and slightly increases thereafter (e.g., Laget et al., 1976; Lauronen et al., 1997; Boor and Goebel, 2000; Gondo et al., 2001; Bercovici et al., 2008; Doria-Lamba et al., 2009; Pihko et al., 2009). These latency changes reflect the increasing neural conduction velocities following myelination and maturation opposed by physical growth of the body and limbs (Müller et al., 1994; Boor and Goebel, 2000; García et al., 2000).

\section{DEVELOPMENT OF LOCAL CORTICAL CIRCUITS AND INTRACORTICAL PROCESSING}

Besides the wiring of thalamo-cortical connections, major developmental changes also occur within the cortex during the second and third trimester as well as postnatally (Marin-Padilla, 1970). Between the 28 and 40th GW, the brain volume more than doubles and cortical gray matter volume extends fourfold (Hüppi et al., 1998b). Postmortem data of human infants show that development of dendrites of cortical pyramidal cells begins during the second trimester from the deeper cortical layers, followed by more superficial layers (Mrzljak et al., 1992). The number of basal dendrites stabilizes around the 27th GW, but their growth in length accelerates during the third trimester and continues postnatally (Mrzljak et al., 1992). Along with dendritic development, the number of synaptic connections increases, starting in the primary sensory areas during the second trimester and proceeding toward higher-order areas. The "boom time" for cortical synaptogenesis in the primary sensory areas extends over the third trimester and the first three postnatal months, resulting in a sixfold increase in synaptic density (Huttenlocher and Dabholkar, 1997). Of intracortical connections in the visual cortex, the first to form are the

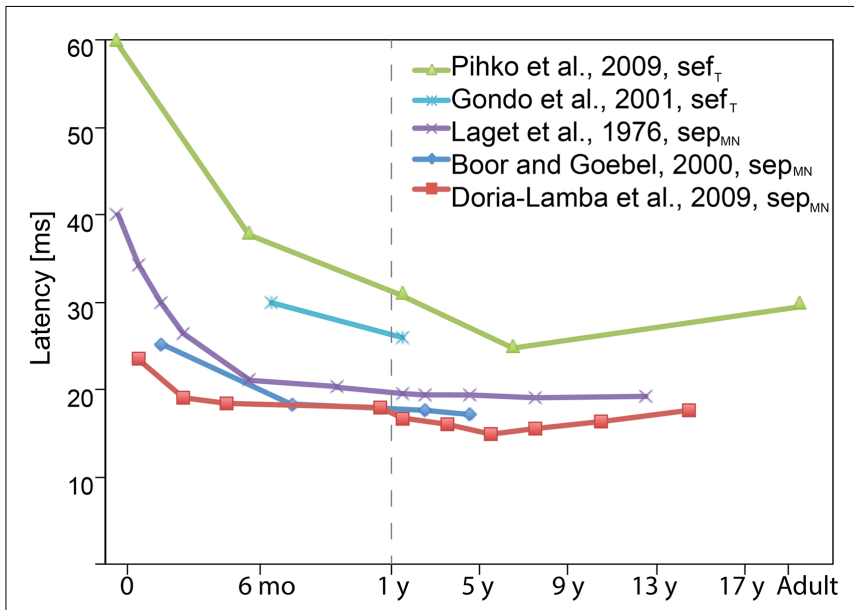

FIGURE 3 | Schematic diagram showing the latency evolution of the earliest cortical $\operatorname{sep}_{\mathrm{MN}} 30$ and sef $_{\mathrm{T}} 30$ components with age as reported in various studies. The general rule is that the $\operatorname{sep}_{\mathrm{MN}} 30$ and $\operatorname{sef}_{\mathrm{T}} 30$ latency decreases until the age of approximately $3-5$ years, and slightly increases thereafter. The absolute latencies vary between studies due to differences in, e.g., stimulation methods and filter settings. Many of the studies also grouped subjects of different ages together in which case the figure displays the midpoint of the reported age range (when the average age was not reported). (Note the different age scales before and after 1 year.)

vertical intracolumnar connections around the 26-29th GW. Horizontal connections follow with intercolumnar projections within layers IVB/V forming around 37th GW and long-range horizontal connections within layer II/III only after 16 postnatal weeks (Burkhalter et al., 1993). These changes in cortical neural structures are also observable in vivo with DTI of the gray matter, where both the mean diffusivity (reflecting an increase in neurite number, cellular complexity, and synapse formation), and fractional anisotropy decline (reflecting an increase in dendritic elongation and branching orthogonal to cortical columns) (Ball et al., 2013). After the third postnatal month, the synaptic density in primary sensory areas decreases gradually, reaching adult levels around puberty (Huttenlocher and Dabholkar, 1997). Some studies on monkeys suggest that the most rapid phase of synapse elimination may occur as late as puberty (Bourgeois and Rakic, 1993).

Marked changes in several neurotransmitter systems also take place around term. One example is the effect of gammaaminobutyric acid (GABA) on the post-synaptic neuron. In the adult brain, GABA is an inhibitory neurotransmitter. At early stages of development, however, $\mathrm{GABA}_{\mathrm{A}}$ receptor activation leads to depolarization (i.e., synaptic excitation) of the post-synaptic neuron due to high intracellular $\mathrm{Cl}^{-}$concentration (Ben-Ari et al., 2004). The change from GABAergic excitation to inhibition in humans likely takes place around or shortly after term (Dzhala et al., 2005).

Evaluating the effects of these changes in the intracortical wiring and "chemistry" of cortical neural processing in vivo is not straight forward, but some inferences can be made from careful examination of neurophysiological data. The deflections following the adult $\mathrm{SEF}_{\mathrm{MN}} 20 / \mathrm{SEP}_{\mathrm{MN}} 20$ or neonatal $\operatorname{sef}_{\mathrm{MN}} 30 /$ sep $_{\mathrm{MN}} 30$ are considered to represent a "higher" level of information processing 
either within local neural circuits of the primary cortical area or in higher-order cortical areas. In a developmental SEP study, Laget and coworkers (Laget et al., 1976) describe substantial changes in

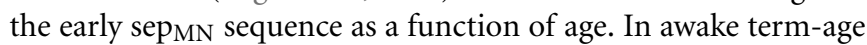

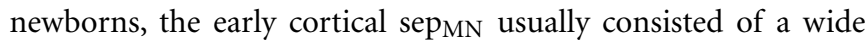
initial surface negative potential in the parietal area, peaking at around $40 \mathrm{~ms}$ and lasting up to $100 \mathrm{~ms}$. Already during the first postnatal month, a notch directed toward the baseline divided this wide neonatal response into two distinct peaks, the first of which peaked at $30 \mathrm{~ms}$. The notch then grew in amplitude with increasing age and crossed the baseline at around 3-4 months of

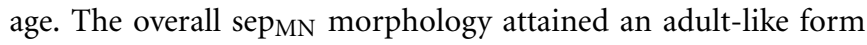
by age 3 years (Laget et al., 1976). However, as only four recording electrodes were used and, consequently, no source modeling was applicable, it is difficult to infer whether the described changes represent the development of local or larger-scale processing.

Modeling the neural sources underlying the early cortical somatosensory responses in MEG has revealed fundamental, qualitative differences in the cortical activity pattern of neonates compared with school-age children or adults. In adults, regardless of the method of somatosensory stimulation, the hallmark of the early SEF in central contralateral areas is a quick transition from the initial, anteriorly pointing dipolar source (i.e., $\mathrm{SEF}_{\mathrm{MN}} 20 / \mathrm{SEF}_{\mathrm{T}} 30$, Figure 2) to a more prominent posteriorly pointing source (i.e., $\mathrm{SEF}_{\mathrm{MN}} 35 / \mathrm{SEF}_{\mathrm{T}} 50$, Figure 2 ). In neonates, no such posteriorly pointing source has been detected at all. Instead, in newborns, the activity of the initial anteriorly pointing source continues over the first $100 \mathrm{~ms}$ after both median nerve and tactile stimulation. This difference between adults and newborns holds with different interstimulus intervals (ISI) as well as different vigilance states (particularly also when adults are examined during sleep) (Nevalainen et al., 2008; Pihko et al., 2009). Thus, the neural populations generating the posteriorly pointing neural current source in adult SI are not similarly activated in neonates.

Some previous neonatal SEP studies seemingly disagree with the MEG data by reporting an "adult-like" initial parietal negativity followed by a positivity in the same area with only slightly prolonged latencies (Willis et al., 1984; Laureau et al., 1988; George and Taylor, 1991). This may, however, be an artificial effect of the highpass filter setting applied in these studies (see Pihko and Lauronen, 2004). Others using a lower highpass cutoff value showed a clearly distinct morphology of early neonatal SEPs compared with those of adults (Desmedt and Manil, 1970; Hrbek et al., 1973; Laget et al., 1976; Karniski, 1992; Karniski et al., 1992). Part of the differences between the SEF and SEP data also naturally arises from the different sources preferentially detected by the two methods: tangential in MEG and both tangential and radial in EEG/SEP.

The exact reason for the lack of a posteriorly pointing SI SEF component in newborns can only be speculated, since no general agreement exists on the cellular-level generation mechanism, even in adults (see, e.g., Huttunen, 1997). Whereas the earliest cortical response $\left(\mathrm{SEF}_{\mathrm{MN}} 20 / \mathrm{SEF}_{\mathrm{T}} 30\right.$ and $\left.\mathrm{SEP}_{\mathrm{MN}} 20\right)$ is generally agreed to represent thalamo-cortical excitation of pyramidal cells in area 3b of SI (Allison et al., 1989a), the mechanism underlying $\mathrm{SEF}_{\mathrm{MN}} 35 / \mathrm{SEF}_{\mathrm{T}} 50$ is not as straight forward. During the $\mathrm{SEF}_{\mathrm{MN}} 35 / \mathrm{SEF}_{\mathrm{T}} 50$, the intracellular current flow is directed from superficial to deeper cortical layers (i.e., opposite to that of $\left.\mathrm{SEF}_{\mathrm{MN}} 20 / \mathrm{SEF}_{\mathrm{T}} 30\right)$. Such intracellular current could be generated by either inhibition in deeper cortical layers (Huttunen and Hömberg, 1991; Wikström et al., 1996; Restuccia et al., 2002; Huttunen et al., 2008), or by excitation of the pyramidal cell apical dendrites in layers I/II (Allison et al., 1989a). In area 1 of monkeys, both mechanisms seem important in the generation of a similar "superficial-to-deep" intracellular current dipole following the initial "deep-to-superficial" dipole (Gardner and Costanzo, 1980; Gardner et al., 1984; Kulics and Cauller, 1986; Cauller and Kulics, 1991; Nicholson Peterson et al., 1995). In newborns, the absence of a posteriorly pointing source could reflect a lack of functional cortico-cortical connectivity necessary for mediating the response, since many of these connections are established postnatally (Burkhalter et al., 1993; Kostovic and Jovanov-Miloševic, 2006). Alternatively, the possibly still immature GABAergic inhibition could result in absence of the posteriorly pointing SI SEF, since such response is also absent in patients with Angelman syndrome, a disorder caused by a deletion in the $\mathrm{GABA}_{\mathrm{A}}$ receptor subunit gene (Egawa et al., 2008). Furthermore, the long-duration of the initial neonatal response might reflect prolonged excitation in the proximal parts of apical dendrites of the pyramidal cells in area $3 \mathrm{~b}$, due to, e.g., slow kinetics of intrinsic membrane conductances (Kim et al., 1995; Moody and Bosma, 2005) and immature neurotransmitter receptors.

Though the exact mechanism for the lack of a posteriorly pointing SI SEF component in newborns remains unclear, it clearly reflects immaturity of somatosensory cortical processing. Consequently, emergence of the posteriorly pointing SI SEF likely reflects maturation of the functional somatosensory network. The transition from the neonatal SI response to the adult-like response occurs gradually during the first couple of years of life (Figure 4, Pihko et al., 2009). By 6 months of age, the originally wide Ushaped neonatal tactile SEF-response has turned into a W-shaped response with an emerging notch (Gondo et al., 2001; Pihko et al., 2009). This notch gradually grows in amplitude and crosses the baseline at around age 2 years, when the field pattern, location and direction of the underling currents begin to resemble those of the adult $\mathrm{SEF}_{\mathrm{MN}} 35 / \mathrm{SEF}_{\mathrm{T}} 50$. After 2 years of age, the morphology of the responses gradually turns into the mature form with the posteriorly pointing source becoming more and the anteriorly pointing less prominent (Figure 4, Pihko et al., 2009). In school-age children and adolescents, the SEF-response sequence (i.e., anteriorly pointing dipolar source followed by a prominent posteriorly pointing source), is very similar to that of adults (Lauronen et al., 1997; Lauronen, 2001; Xiang et al., 2003; Bast et al., 2007; Nevalainen et al., 2012a). In general, the developmental pattern observed with MEG has a lot in common with the SEP morphology development described by Laget et al. (1976). However, the developmental changes occur at a younger age in SEPs than SEFs, for which there are several possible explanations. First, the SEP study used median nerve stimulation, whereas the developmental SEF study applied tactile stimulation of the index finger. Second, the SEP recordings were performed in awake infants and children, whereas SEFs were recorded during sleep. Third, neural activity in gyri may have a greater contribution to the change in SEPs, whereas MEG mainly reflects activity within sulci. For example, the notch in Laget et al.'s (1976) data may represent activity in 


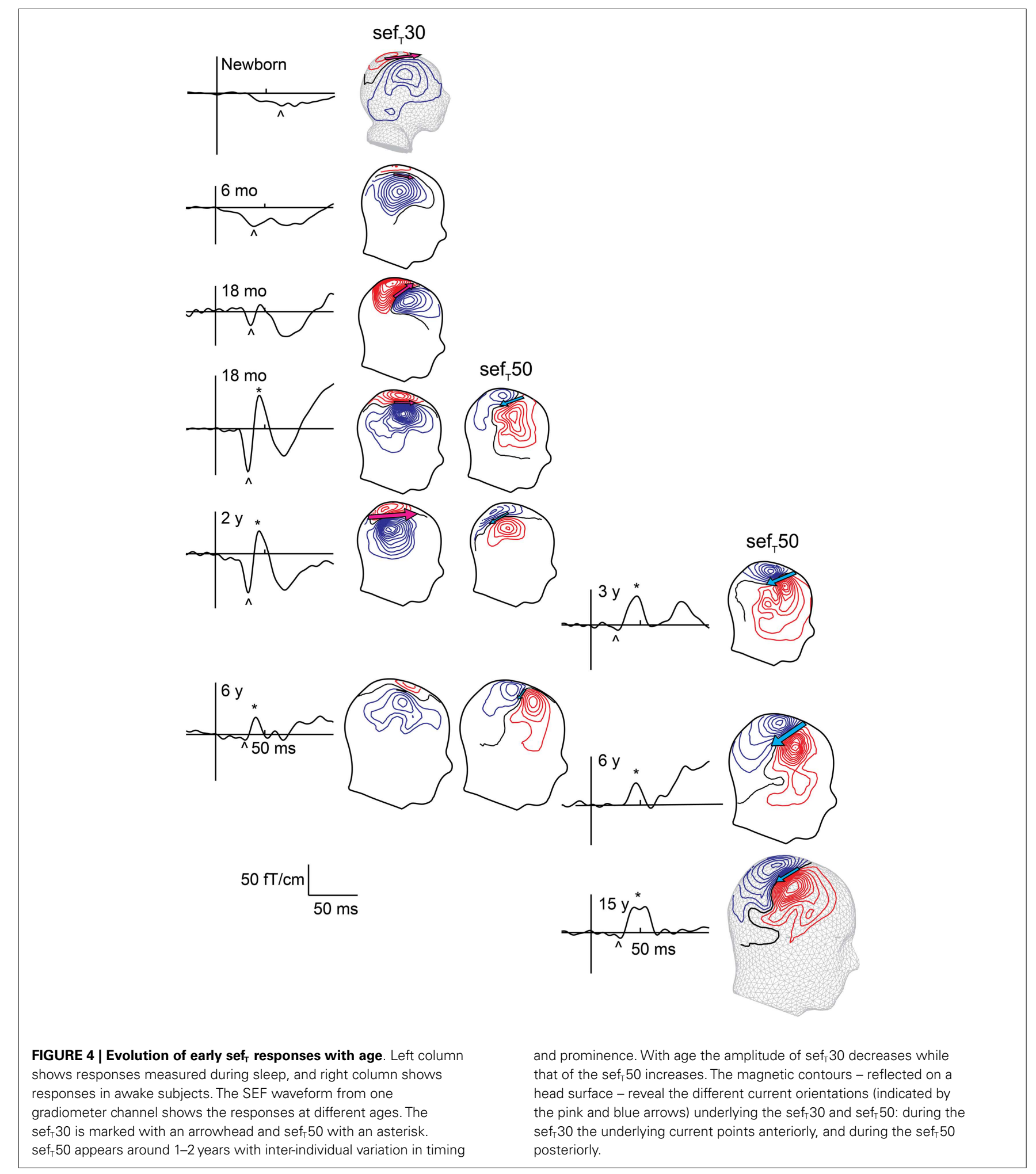

the crown of the postcentral gyrus (area 1), which could go unnoticed in MEG. A combined multielectrode EEG-MEG study would clearly provide invaluable information about the differences and similarities in SEP and SEF development and clarify the underlying developmental phenomena.

\section{INTEGRATION OF SOMATOSENSORY INFORMATION IN LARGE-SCALE CORTICAL NETWORKS}

Relatively little is known about the development of long corticocortical connections and the functionality of large-scale neural networks in the prenatal and neonatal period. In humans, callosal 
unmyelinated fibers are detectable in DTI around the 28th GW (Hüppi et al., 1998a). Postmortem anatomical studies show that after the 35th GW, the long cortico-corticals (e.g., callosal fibers) grow into the cortical plate (Kostovic and Jovanov-Miloševic, 2006). In mice, the region- and layer-specific targeting of callosal projections in the contralateral SI is dependent on electrical excitation and synaptic output of the callosal neurons (Wang et al., 2007). Furthermore, in rhesus monkeys, callosal axons are first overproduced, being three to four times more numerous in newborn than adult monkeys, and their refinement takes place postnatally through callosal axon elimination (LaMantia and Rakic, 1990). Maturation of the callosal connections in humans continues years after birth, as indicated by DTI anisotropy of the corpus callosum, which increases between childhood (7-11 years) and adolescence (15-17 years) (Koerte et al., 2009). Specific knowledge about the development of non-callosal, long cortico-cortical connections is sparse. In general, cortical projection neurons initially have relatively widespread distributions, which become more restricted during development through elimination of functionally inappropriate axon segments and branches (O'Leary et al., 2007).

Recent fMRI data suggest that several resting-state functional networks, including a network encompassing bilateral sensorimotor regions, are present at term-equivalent age (Fransson et al., 2007, 2009; Lin et al., 2008). The neonatal resting-state networks are, however, relatively restricted to homotopic counterparts in the two hemispheres with strong interhemispheric but limited intrahemispheric connectivity, whereas in adults, highly integrated interhemispheric and intrahemispheric connections between disparate regions exist (e.g., Biswal et al., 2010). In general, an increase in strength, complexity, and regional variability of networks are the hallmarks of resting-state fMRI across all periods of development that have been investigated (Lin et al., 2008; Fair et al., 2009; Gao et al., 2009; Supekar et al., 2009; Smyser et al., 2010). Accordingly, the interhemispheric connectivity between the left and right sensorimotor cortices increases both during the preterm period (Doria et al., 2010; Smyser et al., 2010) as well as between birth and age 2 years (Lin et al., 2008; however, see also Liu et al., 2008). Differences in the architecture of the resting-state networks between newborns and adults have also been demonstrated with a graph-theoretical analysis approach to fMRI data. In the adult brain, cortical hubs (brain areas with a disproportionately high degree of functional connectivity, suggesting an important role in the control of information flow) and their related cortical networks are mainly located in higher-order association areas such as posterior cingulate, lateral temporal, lateral parietal, and medial/lateral prefrontal cortices (Achard et al., 2006; Buckner et al., 2009). In contrast, in newborns, cortical hubs and their associated cortical networks are mainly found in primary sensory and motor brain regions (Fransson et al., 2011). However, the restingstate (or background) neural activity during early development and adulthood are different both in terms of generative mechanisms and function. Consequently, the results of developmental resting-state studies using indirect measures of neural activity (such as hemodynamic changes in fMRI) should be interpreted conservatively (Colonnese and Khazipov, 2012). In adults restingstate fMRI activity is thought to reflect the slow modulation of ongoing oscillatory activity generated by dense cortico-cortical networks. During early development (particularly during prematurity), however, the source of the slow fluctuations in resting-state fMRI may reflect alternating periods of electrical silence and bursts generated in sensory networks, driven by spontaneous activity in the periphery that interacts with the thalamo-cortical networks (Colonnese and Khazipov, 2012).

Altogether, studies of resting-state networks and brain anatomy suggest that at the time of full-term birth, the large-scale brain networks are immature and their connectivity patterns restricted. However, both fMRI and MEG studies in newborns have demonstrated ipsilateral SI responses, and MEG studies have revealed bilateral SII responses at term-age.

In fMRI, unilateral passive finger extension-flexion movements elicited BOLD (blood-oxygen-level dependent) responses in contra- and ipsilateral SI without significant differences between the hemispheres. This was interpreted as immature lateralization of somatosensory processing in newborns (Erberich et al., 2006; Heep et al., 2009). MEG responses from ipsilateral SI are detectable only in a minority of healthy newborns, however, and have longer latencies (approximately 20-100 ms) than the contralateral responses (Nevalainen et al., 2008). This suggests that the ipsilateral SEFs are unlikely to represent cortical activation via direct thalamo-cortical pathways, but could be generated through callosal connections that can be relatively abundant at term-age (LaMantia and Rakic, 1990). The millisecond scale latency difference between the contra- and ipsilateral MEG SI activations in neonates would go unnoticed in fMRI, likely explaining the lack of difference between signals at contra- and ipsilateral SI reported by Erberich et al. (2006). Interestingly, at 3 months of age follow-up, the BOLD fMRI signal changes already exhibit an adultlike contralateral SI activation, which persisted at 6 and 9 months (Erberich et al., 2006; Heep et al., 2009). No MEG or EEG reports exist on ipsilateral SI response development in early childhood after the neonatal period.

In adults, unilateral tactile stimulation elicits ipsilateral positive BOLD signals in the posterior parts of SI, probably area 2, in agreement with the bilateral representation of digits in area 2 in monkeys (Fabri et al., 1999; Polonara et al., 1999; Iwamura et al., 2002). With MEG, activation of ipsilateral SI in adult subjects has been detected in some studies (Korvenoja et al., 1995; Kanno et al., 2003; Hadoush et al., 2010; Pihko et al., 2010). Intracranial recordings confirm the presence of ipsilateral SEPs in some epilepsy and tumor patients. In contrast to contralateral responses, they originate only from Brodmann areas 1 and 2 , have longer latencies, smaller amplitudes, and no initial surface negativity or phase reversal across the central sulcus (Allison et al., 1989b; Noachtar et al., 1997). The difference in sensitivity to the direction of underlying currents (mostly radial from area 1) and synchronization of activity could explain why ipsilateral responses from areas 1 and 2 are detected better with fMRI than MEG. Another explanation for the rarely reported ipsilateral SI responses in adults may involve transcallosal inhibition of ipsilateral area $3 \mathrm{~b}$ after unilateral somatosensory stimulation (Hlushchuk and Hari, 2006). In the motor system, transcallosal inhibition is absent in infancy and early childhood (Müller et al., 1997; Heinen et al., 1998). The presence of ipsilateral SI responses 
could reflect lack of transcallosal inhibition in the somatosensory system in early childhood.

Knowledge of somatosensory processing beyond SI was limited before the era of MEG and modern neuroimaging. Since then, these methods have shown that, in the mature somatosensory system, information processing takes place in a wide network, including at least frontoparietal operculum (e.g., the bilateral SII), posterior parietal cortex, and mesial paracentral lobule (see, e.g., Hari and Forss, 1999 for MEG and Disbrow et al., 2000 for fMRI).

Neonatal MEG studies have demonstrated that, after tactile and median nerve stimulation, a prominent deflection in the contralateral hemisphere peaks at about $230 \mathrm{~ms}\left(\operatorname{sef}_{\mathrm{MN}} 230 / \operatorname{sef}_{\mathrm{T}} 230\right.$; Figure 5). The generator source underlying this deflection has been localized to the parietal operculum and thus $\operatorname{sef}_{\mathrm{T}} 230$ most likely represents activity in SII (Pihko et al., 2005; Nevalainen et al., 2008, 2012b). This indicates that the connections to and the neurons in SII are sufficiently developed to produce a detectable SEF response at full-term-age, although with a longer peak latency (approximately $230 \mathrm{~ms}$ ) than in adulthood (approximately $100 \mathrm{~ms}$; e.g., Hari and Forss, 1999). The neonatal SII response does have some similar characteristics with the mature SII response: it is often detectable not only contralaterally but also ipsilaterally and is diminished with the shortening of the ISI (Nevalainen et al., 2008). Interestingly though, the neonatal SII response is particularly prominent in quiet sleep (Pihko et al., 2004; Nevalainen et al., 2008), whereas in adults it is diminished or even vanishes in non-REM sleep (Kitamura et al., 1996; Kakigi et al., 2003; our own unpublished observation). Thus, from an ontogenetic point of view, SII activation in quiet sleep in newborns may have a function in the maturation of the somatosensory neural network. No reports exist about the development of SII responses in early childhood after the neonatal period.

In neonatal SEP studies, several investigators consistently detected a peak at a latency of around $230 \mathrm{~ms}$ (Desmedt and Manil, 1970; Hrbek et al., 1973; Laget et al., 1976; Karniski, 1992; Pihko and Lauronen, 2004; Pihko et al., 2004), with a positivity at the vertex (Desmedt and Manil, 1970; Pihko and Lauronen, 2004; Pihko et al., 2004). Although this SEP response was usually recorded with only a few electrodes, and hence no source modeling was applicable, in retrospect with knowledge from MEG studies, it can be interpreted to represent activity from SII. SEP studies on the evolution of this response with age are also lacking.

\section{EARLY BRAIN INSULTS AND SOMATOSENSORY SYSTEM DEVELOPMENT}

The "age-specific" nervous system of children affects the way in which neural dysfunction presents itself in childhood. First, the lesion types themselves depend on age, since periods of specific neurodevelopmental events are also periods of specific vulnerability. For example, asphyxia in preterm infants preferentially affects periventricular regions, whereas in term infants, cortical regions, thalamus, basal ganglia, and brainstem are more often affected. Second, whereas in adults neurological dysfunction causes specific and localized signs (e.g., hemiplegia in case of stroke in the medial cerebral artery area), in young infants it may present as generalized and non-specific symptoms (e.g., a preterm infant with a unilateral intraventricular hemorrhage (IVH) may present with generalized hypotonia or hypertonia, hypokinesia, or hyperexcitability) (Hadders-Algra, 2004). Furthermore, due to ongoing brain development, the long-term outcome after brain insults occurring prenatally or in early infancy is very different from outcome after an insult occurring in adulthood. The capacity for plastic reorganization after insults is much greater in the developing, immature brain. On the other hand, the mature patterns for information processing that need to be regained after the insult never existed in the immature brain in the first place, and the insult may instead compromise normal developmental processes (Kolb, 1999). The outcome after an early insult is also difficult to predict, since neurodevelopmental changes can induce a disappearance of observed symptoms present at an earlier age. Alternatively, functional deficits may only be recognized with increasing age because of the age-related increase in the complexity of neural functions (Hadders-Algra, 2002). The pathogenic mechanisms leading to the variable neurological deficits after early brain insults are also poorly understood, as in vivo studies of the functional development of the human brain have only been enabled recently
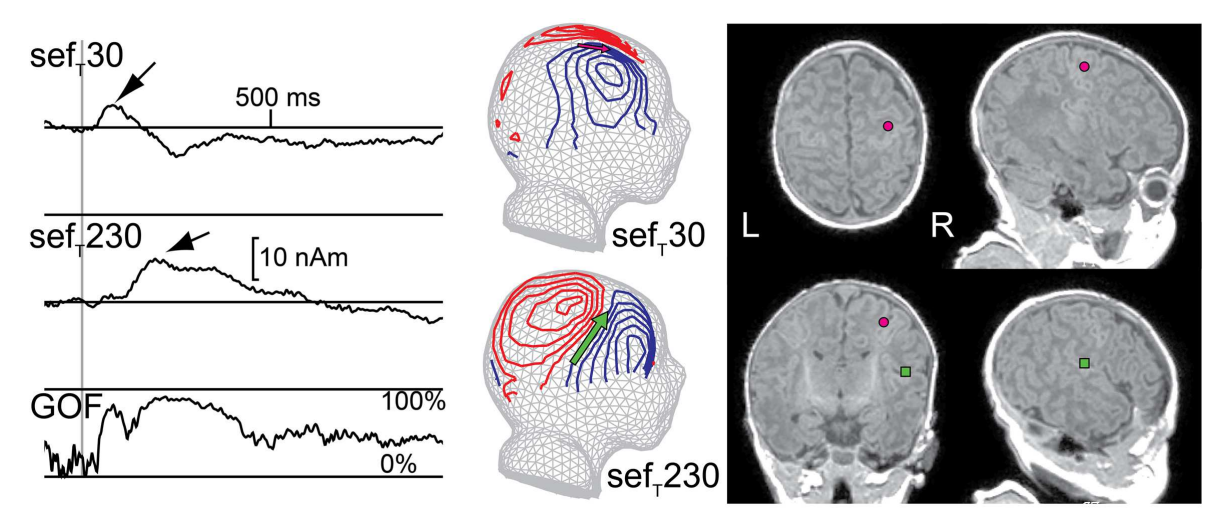

FIGURE 5 | Responses from primary (SI) and secondary (SII) somatosensory areas in a newborn. Left: multidipole model showing SI and SIl source waveforms for the right hemisphere of one newborn. Middle: magnetic field patterns during M60 (SI) and M200 (SII) peaks reflected on a spherical surface and projected onto a schematic newborn head. Right: SI (pink circle) and SII (green square) ECD locations on the newborn's axial, coronal, and sagittal magnetic resonance images (MRIs). (GOF=goodness of fit) 
by non-invasive investigation methods. In pediatric patient populations, MEG studies may, thus, be aimed at resolving questions concerning pathophysiological processes or to find neurophysiological biomarkers for predicting outcome in risk groups. Examples of both approaches are provided in the following sections.

\section{SEFs IN PREDICTING NEURODEVELOPMENTAL OUTCOME IN PRETERM INFANTS}

Although the survival of very preterm infants has increased significantly during recent decades (Vohr et al., 2005), many of these infants still develop with neurological impairments. Neonatal neurological examination is challenged by the non-specificity of signs of neural dysfunction (discussed above) and, consequently, complementary biomarkers for adverse outcome have been sought from neuroimaging and neurophysiology. As the period of active dendritic development and synapse formation is likely to offer better possibilities for rehabilitation than later periods (Kolb, 1999), interventions need to be started at an early age (note, however, the suggested reasons for restricting interventions before term-age: De Graaf-Peters and Hadders-Algra, 2006). Consequently, early prediction of outcome is essential for rehabilitation resources to be offered to those most in need.

Classical risk factors for adverse neurological outcome, including cystic periventricular leukomalacia (PVL) and grade III-IV IVH picked up by cranial ultrasound (Neil and Inder, 2004), are seen ever more rarely, and preterm infants with normal cranial ultrasound may have adverse outcomes (Laptook et al., 2005). At present, the type of pathology suggested to account for most of the neurological problems of preterm infants is diffuse white matter injury (WMI) (Khwaja and Volpe, 2008). WMI is further associated with impaired cerebral cortical development (Inder et al., 1999) and is also likely to lead to impaired development of corticocortical connectivity (Mathur and Inder, 2009). In preterm infants, moderate to severe white matter abnormalities in MRI at termage are associated with severe cognitive and motor dysfunction at 2 years of age (Woodward et al., 2006) and cognitive, language and executive function impairment at 4 and 6 years of age (Woodward et al., 2012).

Furthermore, defects in the microstructural development of the cortex, reflected in DTI as higher mean diffusivity and fractional anisotropy in gray matter in preterm vs. term infants at term-equivalent age, may underlie adverse neurodevelopmental outcome. A slower decline in mean diffusivity during the preterm period was associated with lower overall developmental scores in Griffiths Mental Development Scales at 2 years corrected age (Ball et al., 2013). Moreover, at term-equivalent age, fMRI data have demonstrated significant differences between the resting-state networks of preterm infants and term-born controls. Specifically, functional connectivity between thalamus and sensorimotor cortex was weaker in the preterm infants than in the full-term infants (Smyser et al., 2010).

Possible injury to the thalamo-cortical connections due to periventricular pathology has also motivated a wealth of SEP studies in preterm infants to assess the predictive value of abnormal (absent or delayed depending on the study) median nerve sep $\mathrm{MN}_{\mathrm{N}} 30$ (usually referred to as N1 in the literature; Klimach and Cooke, 1988b; Willis et al., 1989; de Vries et al., 1992; Pierrat et al., 1997) and the earliest posterior tibial nerve SEP (referred to as P1) from SI for future cerebral palsy (CP) (White and Cooke, 1994; Pierrat et al., 1997; Pike and Marlow, 2000). Results have been, however, somewhat contradictory, with specificity, sensitivity, and positive and negative predictive values varying markedly between studies. At least part of this variation is probably explained by differences in patient inclusion criteria, methods of SEP assessment, and outcome measure as well as technical difficulties in reliably recording the responses, particularly in the youngest infants (Smit et al., 2000).

A recent MEG study has expanded the somatosensory response evaluation from SI to SII, thus including cortico-cortical processing assessment. SEFs were recorded at term-age from 39 extremely preterm infants (born $<28 \mathrm{GW}$ ) whose neurodevelopmental outcome was assessed at 2 years corrected age (Rahkonen et al., 2013). MEG data showed that, while SI responses were present in all the preterm infants, the SII response was absent uni- or bilaterally in a third of them. At follow-up, those infants with SII responses missing at term had worse neuromotor and overall developmental scores in the Griffiths Mental Developmental Scales assessment than the preterm infants with normal SII response present at term (Rahkonen et al., 2013). On the contrary, in this study, mild white matter abnormalities in MRI at term-age were not associated with adverse neurodevelopment (the study group did not include infants with moderate/severe WMI) (Rahkonen et al., 2013). It was speculated that the absence of SII responses may reflect not only damage to the connections within the sensorimotor networks but also more widespread disturbances in the development of cortico-cortical connectivity. Behaviorally, SII areas are considered to be involved in the integration of somatic inputs across large portions of the hand, sensorimotor integration, and bimanual coordination (see, e.g., Disbrow et al., 2000 for a discussion), motivating further SII response studies in preterm infants. Many such infants develop with minor neuromotor dysfunction and poor coordination (Hadders-Algra, 2002; Saigal and Doyle, 2008).

\section{MEG INVESTIGATIONS OF SENSORIMOTOR SYSTEM REORGANIZATION AFTER LESIONS TO THE DEVELOPING BRAIN - CP PATIENTS}

Cerebral palsy, caused by an early lesion to the developing brain, is a persistent disorder of movement and posture often accompanied by various sensory deficits. When the early lesion is unilateral and severe enough, in some individuals the sensorimotor networks may develop into an unusual configuration. During normal development, the originally bilateral cortico-spinal motor innervation (Eyre et al., 2001; Eyre, 2003) is reduced to mainly contralateral connections during the first two postnatal years through elimination of most ipsilateral projections. However, after an early unilateral brain insult, the ipsilateral cortico-spinal projections can be, to a great extent, maintained. In such cases of hemiplegic $\mathrm{CP}$, instead of the normal contralateral motor representation, transcranial magnetic stimulation (TMS) may demonstrate bilateral or completely ipsilateral motor representation of the plegic extremity depending on the timing, location, and extent of the lesion (Staudt et al., 2002, 2004, 2006; Eyre, 2007). The mechanisms for preservation of the ipsilateral cortico-spinal projections are thought to involve activity-dependent competition for spinal synaptic space (Eyre, 2007). 
Contrary to the motor system, after both subcortical and cortico-subcortical early brain lesions, primary somatosensory representation of the affected hand generally remains in the contralateral (i.e., ipsilesional) hemisphere as demonstrated by MEG (Gerloff et al., 2006; Staudt et al., 2006; Wilke et al., 2009; Nevalainen et al., 2012a; Pihko et al., 2014), SEPs (Guzzetta et al., 2007), and fMRI (Wilke et al., 2009). Consequently, contralesionally organized motor representation results in the dissociation of somatosensory and motor cortical representations (Staudt et al., 2006; Guzzetta et al., 2007; Wilke et al., 2009). With limited interhemispheric and intrahemispheric reorganization capability, the somatosensory system seems to be particularly vulnerable to lesions extending to the neocortex (Wilke et al., 2009), especially those including areas SI, SII, and/or inferior parietal cortex (Juenger et al., 2011). When the cortex is spared, ascending thalamo-cortical tracts are able to bypass subcortical periventricular white matter lesions, as shown by DTI, and connect to their normal destinations in SI, even in patients with extensive subcortical lesions and ipsilateral motor representation (Staudt et al., 2006). Clinically, somatosensory abilities in such patients are relatively well preserved (Wilke et al., 2009), despite the fact that the fiber count in the thalamo-cortical somatosensory tract may be reduced (Thomas et al., 2005).

In CP patients with unilateral subcortical lesions and contralateral somatosensory representation, somatosensory MEG data reveal alterations in cortical somatosensory processing in both hemispheres (Nevalainen et al., 2012a). First, after median nerve stimulation, the normal activation sequence of SI $\left(\mathrm{SEF}_{\mathrm{MN}} 20\right.$ $\left.\mathrm{SEF}_{\mathrm{MN}} 35\right)$ was disrupted in both hemispheres by an additional peak, $\mathrm{SEF}_{\mathrm{MN}} 25$, with posterior current orientation, preceding a delayed $\mathrm{SEF}_{\mathrm{MN}} 35$. Second, within SI, the cortical representations of contralateral digits II and V were located abnormally close to each other in both hemispheres. Unilateral spatial alterations in the hand representation area have been detected by fMRI, where the area activated by passive hand movement showed larger inter-individual spatial variability in the affected than unaffected hemisphere in patients with CP (Wilke et al., 2009). Third, compared with typically developing adolescents, in the CP patients, SEFs from ipsilateral SI in response to stimulation of the normal hand were more frequent. Thus, the ipsilateral responses in the CP patients do not suggest contralesional (i.e., ipsilateral) reorganization of the somatosensory representation from the affected hand (Nevalainen et al., 2012a). They may, however, reflect another form of unusual organization of the sensorimotor networks and/or lack of the usual ipsilateral area $3 \mathrm{~b}$ inhibition (Hlushchuk and Hari, 2006). Deficient transcallosal inhibition between the motor cortices has been demonstrated with TMS in some (Heinen et al., 1999), though not all, diplegic CP patients (Koerte et al., 2011).

The dissociation of primary motor and somatosensory representations into different hemispheres in some individuals with $\mathrm{CP}$ offers a unique opportunity to study reactivity of sensorimotor oscillations separately from SI and the primary motor area (MI). (Usually, SI and MI locations in the post- and precentral gyri are in such close proximity to each other that separating sources originating from the two areas with certainty in MEG is difficult.) In three CP patients, Gerloff et al. (2006) observed using MEG the corticomuscular coherence to voluntary, paretic hand isometric contraction in the ipsilateral precentral gyrus at a location similar to where TMS evoked responses in the paretic hand muscles. This result suggests that the cortical signal coherent with electromyography during isometric contraction represents the driving volley from MI, and not sensory feedback processing within SI. In another study, in two CP patients with dissociation of motor and somatosensory representations, stimulation of the median nerve of the affected hand did not modulate the sensorimotor betaband oscillations in either hemisphere, even though oscillations in alpha-band were modulated in both hemispheres (Pihko et al., 2014). These data suggest that the somatosensory afferent flow to the contralateral cortex was unable to influence the excitability of the motor cortex in the ipsilateral hemisphere controlling the affected hand.

Discoveries of the large-scale alterations in the wiring of the sensorimotor brain networks in people with CP clearly demonstrate the power of multimodal functional investigation of the developing brain. MEG is an essential tool in the brain development investigation toolbox, particularly when used in combination with other non-invasive methods, such as DTI, fMRI, and TMS. The puzzle of brain network organization after early insults of different scale, timing, and etiology, however, still remains only partly solved. The heterogeneity in this patient population calls for large multi-methodological studies to reveal the principles of vulnerability vs. plastic potential in brain organization after early brain insults.

\section{LIMITATIONS OF MEG IN DEVELOPMENTAL SOMATOSENSORY STUDIES}

Studying children - infants in particular - with MEG or most of the other new non-invasive brain research methods is not and will never become as straightforward as studying adults. First, up to a certain age, only passive paradigms are applicable. Moreover, as most of the new research methods require staying either relatively (e.g., MEG) or completely (e.g., fMRI) still, the youngest subjects can only be studied during sleep (or anesthesia), which requires a lot of time and patience and may alter the results. Furthermore, when studying brain function during sleep, the sleep stage needs to be carefully monitored since the background neural activity changes dramatically between different sleep stages, thus the possible effect of sleep stage on the phenomena of interest cannot be ignored (in fact, it would be rather surprising if sleep stage had no effect). To compare groups, the recordings need to be done at the same vigilance and/or sleep stage, which usually lengthens the recording times. In our experience, most of the failures in infant MEG measurements result from the infant not falling asleep within the reserved time slot.

In addition, we have faced challenges in head position measurement more often in measurements of infants than adults or older children. These problems are likely to arise from the disproportionately large size of the adult sensor helmet compared with the newborn's head, resulting in a longer distance between some of the position indicator coils and the MEG sensors and, consequently, worse signal-to-noise ratio for the head position measurement. For reliable SEF recordings, the head of a newborn/infant needs to be close to the surface of the measuring helmet (Gaetz et al., 2008). With an adult-sized sensor array, this is possible only for 


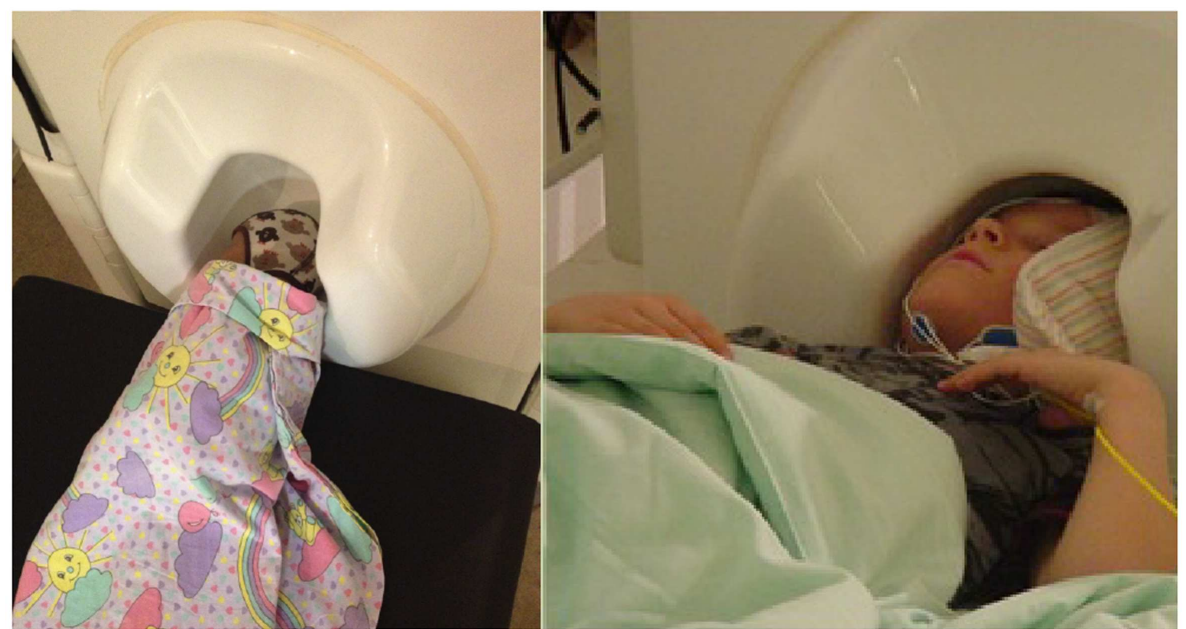

FIGURE 6 | Positioning infants and children in the MEG sensor array for somatosensory recordings. Left: the head of a newborn can be positioned sideways in an adult-size MEG helmet so that one hemisphere is close to the sensors (occipital part of the helmet) and activity from that hemisphere can be recorded. Right: 6-year-old child sleeping with his head in an adult-size helmet. The head is positioned close to the right side of the helmet, the left hemisphere is further away from the sensors, and a small pillow fills the gap, restricting head movements. one hemisphere at a time (Figure 6). The babySQUID, a special MEG instrument with infant-size but open headrest covering only part of one hemisphere, has the same problem (Okada et al., 2006; Papadelis et al., 2013). Thus, the number of possible paradigms in infants is reduced as, e.g., recording from both hemispheres simultaneously is not feasible. This doubles the measurement time when both ipsilateral and contralateral activity is of interest and largely prevents studies of interhemispheric interactions. Recently developed pediatric-sized measuring helmets have already proven successful in studying pre-school-age children (Johnson et al., 2010; Tesan et al., 2010) and are likely to considerably enhance the variability of possible paradigms for future MEG studies in the smallest subjects once still smaller helmets become commercially available (Edgar et al., 2012; see also Roberts et al., 2014 in this Research Topic).

Possible head movements during the measurement constitute another important issue in developmental MEG studies. Conducting recordings during sleep in the smallest subjects compensates for most of the movements, and continuous head position measurement likely deals with twitches during sleep (Taulu et al., 2004; Wehner et al., 2008). However, experience in applying continuous head position measurement in infants is at the moment sparse (Imada et al., 2006; Bosseler et al., 2013). In addition, artifacts in MEG produced by the electrical MN stimulation are greater in newborns, due to the proximity of the stimulation electrodes to the sensors. Therefore, non-electric tactile stimuli for somatosensory studies have turned out to be a good alternative in studies of infants.

As a clinical tool in our hospital, MEG is only used in a very limited number of patients, mainly those considered for epilepsy surgery to localize epileptic foci (e.g., Wilenius et al., 2013). MEG can also be used to localize the SI as part of pre-surgical functional mapping (e.g., Ochi and Otsubo, 2008; Tovar-Spinoza et al., 2008). In order for MEG to become a valuable tool for other purposes in the field of clinical neonatology or pediatrics, major developments in both machinery and analysis methods are still required. The devices should be mobile or located closer to neonatal units to allow studies of sick infants, and - in an optimal future scenario - the measurement helmet would be adjustable to the child's head size. Furthermore, more automated analysis pipelines would greatly facilitate the possibility of using MEG as a tool to detect abnormality in neonatal brain activity.

\section{CONCLUSION AND FUTURE PROSPECTS}

In the last decade, MEG has provided a wealth of new information about normal and abnormal development of somatosensory cortical processing in early infancy, which would have been very hard to infer using other methods. Thus, a solid ground has been established to investigate the developing brain using MEG. With the somatosensory system, new information related to SII responses provides opportunities for studying higher cortical processing in neonates at risk for adverse outcome. Since neonatal care has significantly improved in the last decades, there is a growing need to detect the subtle disturbances that possibly cause problems in higher cortical functions but are evident clinically only later in life, e.g., during school years. MEG as a technique offers great possibilities for studying the pathophysiologic mechanisms underlying such subtle disturbances from a neuroscientific perspective.

\section{AUTHOR CONTRIBUTIONS}

Päivi Nevalainen had the main responsibility of writing the manuscript and preparing the figures. Leena Lauronen and Elina Pihko helped to design the outline and content of the manuscript and edited the manuscript and figures. Elina Pihko also prepared Figures 4 and 6.

\section{ACKNOWLEDGMENTS}

We thank Professors Helena Pihko and Riitta Hari for useful comments on the manuscript, Dr Cathy Nangini for language 
editing, and Professor Lauri Parkkonen for the baby mesh. The study was financially supported by the aivoAALTO project of Aalto University.

\section{REFERENCES}

Achard, S., Salvador, R., Whitcher, B., Suckling, J., and Bullmore, E. (2006). A resilient, low-frequency, small-world human brain functional network with highly connected association cortical hubs. J. Neurosci. 26, 63-72. doi:10.1523/ JNEUROSCI.3874-05.2006

Allison, T., McCarthy, G., Wood, C. C., Darcey, T. M., Spencer, D. D., and Williamson, P. D. (1989a). Human cortical potentials evoked by stimulation of the median nerve. I. Cytoarchitectonic areas generating short-latency activity. J. Neurophysiol. 62, 694-710.

Allison, T., McCarthy, G., Wood, C. C., Darcey, T. M., Spencer, D. D., and Williamson, P. D. (1989b). Human cortical potentials evoked by stimulation of the median nerve. II. Cytoarchitectonic areas generating long-latency activity. J. Neurophysiol. 62, 711-722.

Ball, G., Srinivasan, L., Aljabar, P., Counsell, S. J., Durighel, G., Hajnal, J. V., et al. (2013). Development of cortical microstructure in the preterm human brain. Proc. Natl. Acad. Sci. U.S.A. 110, 9541-9546. doi:10.1073/pnas.1301652110

Bast, T., Wright, T., Boor, R., Harting, I., Feneberg, R., Rupp, A., et al. (2007). Combined EEG and MEG analysis of early somatosensory evoked activity in children and adolescents with focal epilepsies. Clin. Neurophysiol. 118, 1721-1735. doi:10.1016/j.clinph.2007.03.037

Ben-Ari, Y., Khalilov, I., Represa, A., and Gozlan, H. (2004). Interneurons set the tune of developing networks. Trends Neurosci. 27, 422-427. doi:10.1016/j.tins. 2004.05.002

Bercovici, E., Pang, E. W., Sharma, R., Mohamed, I. S., Imai, K., Fujimoto, A., et al. (2008). Somatosensory-evoked fields on magnetoencephalography for epilepsy infants younger than 4 years with total intravenous anesthesia. Clin. Neurophysiol. 119, 1328-1334. doi:10.1016/j.clinph.2008.02.018

Berman, J. I., Mukherjee, P., Partridge, S. C., Miller, S. P., Ferriero, D. M., Barkovich, A. J., et al. (2005). Quantitative diffusion tensor MRI fiber tractography of sensorimotor white matter development in premature infants. Neuroimage 27, 862-871. doi:10.1016/j.neuroimage.2005.05.018

Biswal, B. B., Mennes, M., Zuo, X.-N., Gohel, S., Kelly, C., Smith, S. M., et al. (2010). Toward discovery science of human brain function. Proc. Natl. Acad. Sci. U.S.A. 107, 4734-4739. doi:10.1073/pnas.0911855107

Boor, R., and Goebel, B. (2000). Maturation of near-field and far-field somatosensory evoked potentials after median nerve stimulation in children under 4 years of age. Clin. Neurophysiol. 111, 1070-1081. doi:10.1016/S1388-2457(00)00262-5

Bosseler, A. N., Taulu, S., Pihko, E., Mäkelä, J. P., Imada, T., Ahonen, A., et al. (2013). Theta brain rhythms index perceptual narrowing in infant speech perception. Front. Psychol. 4:690. doi:10.3389/fpsyg.2013.00690

Bourgeois, J., and Rakic, P. (1993). Changes of synaptic density in the primary visual cortex of the macaque monkey from fetal to adult stage. J. Neurosci. 13, 2801-2820.

Brody, B. A., Kinney, H. C., Kloman, A. S., and Gilles, F. H. (1987). Sequence of central nervous system myelination in human infancy. I. An autopsy study of myelination. J. Neuropathol. Exp. Neurol. 46, 283-301. doi:10.1097/00005072198705000-00005

Buckner, R. L., Sepulcre, J., Talukdar, T., Krienen, F. M., Liu, H., Hedden, T., et al. (2009). Cortical hubs revealed by intrinsic functional connectivity: mapping, assessment of stability, and relation to Alzheimer's disease. J. Neurosci. 29, 1860-1873. doi:10.1523/JNEUROSCI.5062-08.2009

Burkhalter, A., Bernardo, K. L., and Charles, V. (1993). Development of local circuits in human visual cortex. J. Neurosci. 13, 1916-1931.

Cauller, L. J., and Kulics, A. T. (1991). The neural basis of the behaviorally relevant $\mathrm{N} 1$ component of the somatosensory-evoked potential in SI cortex of awake monkeys: evidence that backward cortical projections signal conscious touch sensation. Exp. Brain Res. 84, 607-619. doi:10.1007/BF00230973

Colonnese, M., and Khazipov, R. (2012). Spontaneous activity in developing sensory circuits: implications for resting state fMRI. Neuroimage 62, 2212-2221. doi:10.1016/j.neuroimage.2012.02.046

De Graaf-Peters, V. B., and Hadders-Algra, M. (2006). Ontogeny of the human central nervous system: what is happening when? Early Hum. Dev. 82, 257-266. doi:10.1016/j.earlhumdev.2005.10.013

de Vries, L. S., Eken, P., Pierrat, V., Daniels, H., and Casaer, P. (1992). Prediction of neurodevelopmental outcome in the preterm infant: short latency cortical somatosensory evoked potentials compared with cranial ultrasound. Arch. Dis. Child.67, 1177-1181. doi:10.1136/adc.67.10_Spec_No.1177

Desmedt, J. E., and Manil, J. (1970). Somatosensory evoked potentials of the normal human neonate in REM sleep, in slow wave sleep and in waking. Electroencephalogr. Clin. Neurophysiol. 29, 113-126. doi:10.1016/0013-4694(70)90114-8

Disbrow, E., Roberts, T. I. M., and Krubitzer, L. (2000). Somatotopic organization of cortical fields in the lateral sulcus of Homo sapiens: evidence for SII and PV. J. Comp. Neurol. 418, 1-21. doi:10.1002/(SICI)1096-9861(20000228)418:1<1: :AID-CNE1>3.0.CO;2-P

Doria, V., Beckmann, C. F., Arichi, T., Merchant, N., Groppo, M., Turkheimer, F. E., et al. (2010). Emergence of resting state networks in the preterm human brain. Proc. Natl. Acad. Sci. U.S.A. 107, 20015-20020. doi:10.1073/pnas.1007921107

Doria-Lamba, L., Montaldi, L., Grosso, P., Veneselli, E., and Giribaldi, G. (2009). Short latency evoked somatosensory potentials after stimulation of the median nerve in children: normative data. J. Clin. Neurophysiol. 26, 176-182. doi:10. 1097/WNP.0b013e3181a76a56

Dzhala, V. I., Talos, D. M., Sdrulla, D. A., Brumback, A. C., Mathews, G. C., Benke, T. A., et al. (2005). NKCC1 transporter facilitates seizures in the developing brain. Nat. Med. 11, 1205-1213. doi:10.1038/nm1301

Edgar, J., Paulson, P., Hirschkoff, E., Pratt, K., Mascarenas, A., Miller, P., et al. (2012). "Artemis 123: development of a whole-head infant MEG system," in 18th International Conference on Biomagnetism, Paris.

Egawa, K., Asahina, N., Shiraishi, H., Kamada, K., Takeuchi, F., Nakane, S., et al. (2008). Aberrant somatosensory-evoked responses imply GABAergic dysfunction in Angelman syndrome. Neuroimage 39, 593-599. doi:10.1016/j. neuroimage.2007.09.006

Erberich, S. G., Panigrahy, A., Friedlich, P., Seri, I., Nelson, M. D., and Gilles, F. (2006). Somatosensory lateralization in the newborn brain. Neuroimage 29, 155-161. doi:10.1016/j.neuroimage.2005.07.024

Eyre, J. A. (2003). Development and plasticity of the corticospinal system in man. Neural Plast. 10, 93-106. doi:10.1155/NP.2003.93

Eyre, J. A. (2007). Corticospinal tract development and its plasticity after perinatal injury. Neurosci. Biobehav. Rev. 31, 1136-1149. doi:10.1016/j.neubiorev. 2007.05.011

Eyre, J. A., Taylor, J. P., Villagra, F., Smith, M., and Miller, S. (2001). Evidence of activity-dependent withdrawal of corticospinal projections during human development. Neurology 57, 1543-1554. doi:10.1212/WNL.57.9.1543

Fabri, M., Polonara, G., Quattrini, A., Salvolini, U., Del Pesce, M., and Manzoni, T. (1999). Role of the corpus callosum in the somatosensory activation of the ipsilateral cerebral cortex: an fMRI study of callosotomized patients. Eur. J. Neurosci. 11, 3983-3994. doi:10.1046/j.1460-9568.1999.00829.x

Fair, D. A., Cohen, A. L., Power, J. D., Dosenbach, N. U. F., Church, J. A., Miezin, F. M., et al. (2009). Functional brain networks develop from a "local to distributed" organization. PLoS Comput. Biol. 5:e1000381. doi:10.1371/journal.pcbi.1000381

Fransson, P., Åden, U., Blennow, M., and Lagercrantz, H. (2011). The functional architecture of the infant brain as revealed by resting-state fMRI. Cereb. Cortex 21, 145-154. doi:10.1093/cercor/bhq071

Fransson, P., Skiöld, B., Engström, M., Hallberg, B., Mosskin, M., Åden, U., et al. (2009). Spontaneous brain activity in the newborn brain during natural sleep - an fMRI study in infants born at full term. Pediatr. Res. 66, 301-305. doi:10.1203/PDR.0b013e3181b1bd84

Fransson, P., Skiöld, B., Horsch, S., Nordell, A., Blennow, M., Lagercrantz, H., et al. (2007). Resting-state networks in the infant brain. Proc. Natl. Acad. Sci. U.S.A. 104, 15531-15536. doi:10.1073/pnas.0704380104

Gaetz, W., Otsubo, H., and Pang, E. W. (2008). Magnetoencephalography for clinical pediatrics: the effect of head positioning on measurement of somatosensory-evoked fields. Clin. Neurophysiol. 119, 1923-1933. doi:10.1016/j. clinph.2008.04.291

Gao, W., Zhu, H., Giovanello, K. S., Smith, J. K., Shen, D., Gilmore, J. H., et al. (2009). Evidence on the emergence of the brain's default network from 2-week-old to 2year-old healthy pediatric subjects. Proc. Natl. Acad. Sci. U.S.A. 106, 6790-6795. doi:10.1073/pnas.0811221106

García, A., Calleja, J., Antolín, F. M., and Berciano, J. (2000). Peripheral motor and sensory nerve conduction studies in normal infants and children. Clin. Neurophysiol. 111, 513-520. doi:10.1016/S1388-2457(99)00279-5

Gardner, E. P., and Costanzo, R. M. (1980). Temporal integration of multiple-point stimuli in primary somatosensory cortical receptive fields of alert monkeys. J. Neurophysiol. 43, 444-468.

Gardner, E. P., Hämäläinen, H. A., Warren, S., Davis, J., and Young, W. (1984). Somatosensory evoked potentials (SEPs) and cortical single unit responses 
elicited by mechanical tactile stimuli in awake monkeys. Electroencephalogr. Clin. Neurophysiol. 58, 537-552. doi:10.1016/0013-4694(84)90044-0

George, S., and Taylor, M. J. (1991). Somatosensory evoked potentials in neonates and infants: developmental and normative data. Electroencephalogr. Clin. Neurophysiol. 80, 94-102. doi:10.1016/0168-5597(91)90146-O

Gerloff, C., Braun, C., Staudt, M., Hegner, Y. L., Dichgans, J., and Krägeloh-Mann, I. (2006). Coherent corticomuscular oscillations originate from primary motor cortex: evidence from patients with early brain lesions. Hum. Brain Mapp. 27, 789-798. doi:10.1002/hbm.20220

Gibson, N., Brezinova, V., and Levene, M. (1992). Somatosensory evoked potentials in the term newborn. Electroencephalogr. Clin. Neurophysiol. 84, 26-31. doi:10.1016/0168-5597(92)90065-J

Gondo, K., Tobimatsu, S., Kira, R., Tokunaga, Y., Yamamoto, T., and Hara, T. (2001). A magnetoencephalographic study on development of the somatosensory cortex in infants. Neuroreport 12, 3227-3231. doi:10.1097/00001756-200110290-00017

Guzzetta, A., Bonanni, P., Biagi, L., Tosetti, M., Montanaro, D., Guerrini, R., et al. (2007). Reorganisation of the somatosensory system after early brain damage. Clin. Neurophysiol. 118, 1110-1121. doi:10.1016/j.clinph.2007.02.014

Hadders-Algra, M. (2002). Two distinct forms of minor neurological dysfunction: perspectives emerging from a review of data of the Groningen Perinatal Project. Dev. Med. Child Neurol. 44, 561-571. doi:10.1111/j.1469-8749.2002.tb00330.x

Hadders-Algra, M. (2004). General movements: a window for early identification of children at high risk for developmental disorders. J. Pediatr. 145, S12-S18. doi:10.1016/j.jpeds.2004.05.017

Hadoush, H., Inoue, K., Nakanishi, K., Kurumadani, H., Sunagawa, T., and Ochi, M. (2010). Ipsilateral primary sensorimotor cortical response to mechanical tactile stimuli. Neuroreport 21, 108-113. doi:10.1097/WNR.0b013e3283349a17

Hämäläinen, M., Hari, R., Ilmoniemi, R., Knuutila, J., and Lounasmaa, O. (1993). Magnetoencephalography - theory, instrumentation, and applications to noninvasive studies of the working human brain. Rev. Mod. Phys. 65, 413-497. doi:10.1103/RevModPhys.65.413

Hari, R., and Forss, N. (1999). Magnetoencephalography in the study of human somatosensory cortical processing. Philos. Trans. R. Soc. Lond. B Biol. Sci. 354, 1145-1154. doi:10.1098/rstb.1999.0470

Heep, A., Scheef, L., Jankowski, J., Born, M., Zimmermann, N., Sival, D., et al. (2009). Functional magnetic resonance imaging of the sensorimotor system in preterm infants. Pediatr. 123, 294-300. doi:10.1542/peds.2007-3475

Heinen, F., Glocker, F.-X., Fietzek, U., Meyer, B., Lücking, C., and Korinthenberg, R. (1998). Absence of transcallosal inhibition following focal magnetic stimulation in preschool children. Ann. Neurol. 43, 608-612. doi:10.1002/ana.410430508

Heinen, F., Kirschner, J., Fietzek, U., Glocker, F. X., Mall, V., and Korinthenberg, R. (1999). Absence of transcallosal inhibition in adolescents with diplegic cerebral palsy. Muscle Nerve 22, 255-257. doi:10.1002/(SICI)1097-4598(199902)22: 2<255::AID-MUS14>3.0.CO;2-7

Herlenius, E., and Lagercrantz, H. (2004). Development of neurotransmitter systems during critical periods. Exp. Neurol. 190(Suppl.), S8-S21. doi:10.1016/j. expneurol.2004.03.027

Hlushchuk, Y., and Hari, R. (2006). Transient suppression of ipsilateral primary somatosensory cortex during tactile finger stimulation. J. Neurosci. 26, 5819-5824. doi:10.1523/JNEUROSCI.5536-05.2006

Hrbek, A., Karlberg, P., and Olsson, T. (1973). Development of visual and somatosensory evoked responses in pre-term newborn infants. Electroencephalogr. Clin. Neurophysiol. 34, 225-232. doi:10.1016/0013-4694(73)90249-6

Huotilainen, M. (2006). Magnetoencephalography of the newborn brain. Semin. Fetal Neonatal Med. 11, 437-443. doi:10.1016/j.siny.2006.07.003

Hüppi, P. S., Maier, S. E., Peled, S., Zientara, G. P., Barnes, P. D., Jolesz, F. A., et al. (1998a). Microstructural development of human newborn cerebral white matter assessed in vivo by diffusion tensor magnetic resonance imaging. Pediatr. Res. 44, 584-590. doi:10.1203/00006450-199810000-00019

Hüppi, P. S., Warfield, S., Kikinis, R., Barnes, P. D., Zientara, G. P., Jolesz, F. A., et al. (1998b). Quantitative magnetic resonance imaging of brain development in premature and mature newborns. Ann. Neurol. 43, 224-235. doi:10.1002/ana. 410430213

Huttenlocher, P. R., and Dabholkar, A. S. (1997). Regional differences in synaptogenesis in human cerebral cortex. J. Comp. Neurol. 387, 167-178. doi:10.1002/ (SICI) 1096-9861(19971020)387:23.0.CO;2-Z

Huttunen, J. (1997). Does the P35m SEF deflection really come from the motor cortex? Electroencephalogr. Clin. Neurophysiol. 104, 101-102.
Huttunen, J., and Hömberg, V. (1991). Influence of stimulus repetition rate on cortical somatosensory potentials evoked by median nerve stimulation: implications for generation mechanisms. J. Neurol. Sci. 105, 37-43. doi:10.1016/0022510X(91)90115-N

Huttunen, J., Pekkonen, E., Kivisaari, R., Autti, T., and Kähkönen, S. (2008). Modulation of somatosensory evoked fields from SI and SII by acute GABA Aagonism and paired-pulse stimulation. Neuroimage 40, 427-434. doi:10.1016/ j.neuroimage.2007.12.024

Iai, M., Yamamura, T., and Takashima, S. (1997). Early expression of proteolipid protein in human fetal and infantile cerebri. Pediatr. Neurol. 8994, 235-239. doi:10.1016/S0887-8994(97)00099-4

Imada, T., Zhang, Y., Cheour, M., Taulu, S., Ahonen, A., and Kuhl, P. K. (2006). Infant speech perception activates Broca's area: a developmental magnetoencephalography study. Neuroreport 17, 957-962. doi:10.1097/01.wnr.0000223387.51704.89

Inder, T. E., Hüppi, P. S., Warfield, S., Kikinis, R., Zientara, G. P., Barnes, P. D., et al. (1999). Periventricular white matter injury in the premature infant is followed by reduced cerebral cortical gray matter volume at term. Ann. Neurol. 46, 755-760. doi:10.1002/1531-8249(199911)46:53.0.CO;2-0

Iwamura, Y., Tanaka, M., Iriki, A., Taoka, M., and Toda, T. (2002). Processing of tactile and kinesthetic signals from bilateral sides of the body in the postcentral gyrus of awake monkeys. Behav. Brain Res. 135, 185-190. doi:10.1016/S01664328(02)00164-X

Johnson, B. W., Crain, S., Thornton, R., Tesan, G., and Reid, M. (2010). Measurement of brain function in pre-school children using a custom sized whole-head MEG sensor array. Clin. Neurophysiol. 121, 340-349. doi:10.1016/j.clinph.2009. 10.017

Juenger, H., de Haan, B., Krägeloh-Mann, I., Staudt, M., and Karnath, H.-O. (2011). Early determination of somatosensory cortex in the human brain. Cereb. Cortex 21, 1827-1831. doi:10.1093/cercor/bhq258

Kakigi, R., Naka, D., Okusa, T., Wang, X., Inui, K., Qiu, Y., et al. (2003). Sensory perception during sleep in humans: a magnetoencephalograhic study. Sleep Med. 4, 493-507. doi:10.1016/S1389-9457(03)00169-2

Kanno, A., Nakasato, N., Hatanaka, K., and Yoshimoto, T. (2003). Ipsilateral area 3b responses to median nerve somatosensory stimulation. Neuroimage 18, 169-177. doi:10.1006/nimg.2002.1283

Kanold, P. O. (2009). Subplate neurons: crucial regulators of cortical development and plasticity. Front. Neuroanat. 3:16. doi:10.3389/neuro.05.016.2009

Karniski, W. (1992). The late somatosensory evoked potential in premature and term infants. I. Principal component topography. Electroencephalogr. Clin. Neurophysiol. 84, 32-43. doi:10.1016/0168-5597(92)90066-K

Karniski, W., Wyble, L., Lease, L., and Blair, R. (1992). The late somatosensory evoked potential in premature and term infants. II. Topography and latency development. Electroencephalogr. Clin. Neurophysiol. 84, 44-54. doi:10.1016/01685597(92)90066-K

Khwaja, O., and Volpe, J. J. (2008). Pathogenesis of cerebral white matter injury of prematurity. Arch. Dis. Child. Fetal Neonatal Ed. 93, 1-20. doi:10.1136/adc.2006. 108837

Kim, H., Fox, K., and Connors, B. (1995). Properties of excitatory synaptic events in neurons of primary somatosensory cortex of neonatal rats. Cereb. Cortex 5 , 148-157. doi:10.1093/cercor/5.2.148

Kitamura, Y., Kakigi, R., Hoshiyama, M., Koyama, S., and Nakamura, A. (1996). Effects of sleep on somatosensory evoked responses in human: a magnetoencephalographic study. Brain Res. Cogn. Brain Res. 4, 275-279. doi:10.1016/S09266410(96)00066-3

Klimach, V. J., and Cooke, R. W. (1988a). Maturation of the neonatal somatosensory evoked response in preterm infants. Dev. Med. Child Neurol. 30, 208-214. doi:10.1111/j.1469-8749.1988.tb04752.x

Klimach, V. J., and Cooke, R. W. (1988b). Short-latency cortical somatosensory evoked responses of preterm infants with ultrasound abnormality of the brain. Dev. Med. Child Neurol. 30, 215-221. doi:10.1111/j.1469-8749.1988.tb04753.x

Koerte, I., Heinen, F., Fuchs, T., Laubender, R. P., Pomschar, A., Stahl, R., et al. (2009). Anisotropy of callosal motor fibers in combination with transcranial magnetic stimulation in the course of motor development. Invest. Radiol. 44, 279-284. doi:10.1097/RLI.0b013e31819e9362

Koerte, I., Pelavin, P., Kirmess, B., Fuchs, T., Berweck, S., Laubender, R. P., et al. (2011). Anisotropy of transcallosal motor fibres indicates functional impairment in children with periventricular leukomalacia. Dev. Med. Child Neurol. 53, 179-186. doi:10.1111/j.1469-8749.2010.03840.x 
Kolb, B. (1999). Synaptic plasticity and the organization of behaviour after early and late brain injury. Can. J. Exp. Psychol. 53, 62-75. doi:10.1037/h0087300

Korvenoja, A., Wikström, H., Huttunen, J., Virtanan, J., Laine, P., Aronen, H. J., et al. (1995). Activation of ipsilateral primary sensorimotor cortex by median nerve stimulation. Neuroreport 6, 2589-2593. doi:10.1097/00001756199512150-00033

Kostovic, I., and Jovanov-Miloševic, N. (2006). The development of cerebral connections during the first 20-45 weeks' gestation. Semin. Fetal Neonatal Med. 11, 415-422. doi:10.1016/j.siny.2006.07.001

Kostovic, I., Judas, M., Petanjek, Z., and Simic, G. (1995). Ontogenesis of goaldirected behavior: anatomo-functional considerations. Int. J. Psychophysiol. 19, 85-102. doi:10.1016/0167-8760(94)00081-O

Kostovic, I., and Rakic, P. (1990). Developmental history of the transient subplate zone in the visual and somatosensory cortex of the macaque monkey and human brain. J. Comp. Neurol. 297, 441-470. doi:10.1002/cne.902970309

Kulics, A. T., and Cauller, L. J. (1986). Cerebral cortical somatosensory evoked responses, multiple unit activity and current source-densities: their interrelationships and significance to somatic sensation as revealed by stimulation of the awake monkey's hand. Exp. Brain Res. 62, 46-60. doi:10.1007/BF00237402

Laget, P., Raimbault, J., D’Allest, A. M., Flores-Guevara, R., Mariani, J., and ThieriotPrevost, G. (1976). Maturation of somesthetic evoked potentials in man. Electroencephalogr. Clin. Neurophysiol. 40, 499-515. doi:10.1016/0013-4694(76) 90080- 8

LaMantia, A., and Rakic, P. (1990). Axon overproduction and elimination developing rhesus monkey in the corpus callosum of the rhesus monkey. J. Neurosci. 10, 2156-2175.

Laptook, A. R., O'Shea, T. M., Shankaran, S., and Bhaskar, B. (2005). Adverse neurodevelopmental outcomes among extremely low birth weight infants with a normal head ultrasound: prevalence and antecedents. Pediatrics 115, 673-680. doi:10.1542/peds.2004-0667

Laureau, E., Majnemer, A., Rosenblatt, B., and Riley, P. (1988). A longitudinal study of short latency somatosensory evoked responses in healthy newborns and infants. Electroencephalogr. Clin. Neurophysiol. 71, 100-108. doi:10.1016/0168-5597(88) 90011-1

Laureau, E., and Marlot, D. (1990). Somatosensory evoked potentials after median and tibial nerve stimulation in healthy newborns. Electroencephalogr. Clin. Neurophysiol. 76, 453-458. doi:10.1016/0013-4694(90)90098-5

Lauronen, L. (2001). Neuromagnetic Studies on Somatosensory Functions in CLN3, CLN5 and CLN8 forms of Neuronal Ceroid Lipofuscinoses. Academic Dissertation, University of Helsinki, Helsinki, 35-36.

Lauronen, L., Heikkilä, E., Autti, T., Sainio, K., Huttunen, J., Aronen, H. J., et al. (1997). Somatosensory evoked magnetic fields from primary sensorimotor cortex in juvenile neuronal ceroid lipofuscinosis. J. Child Neurol. 12, 355-360. doi:10.1177/088307389701200603

Lauronen, L., Nevalainen, P., and Pihko, E. (2011). Magnetoencephalography in neonatology. Neurophysiol. Clin. 42, 27-34. doi:10.1016/j.neucli.2011.08.006

Lauronen, L., Nevalainen, P., Wikström, H., Parkkonen, L., Okada, Y., and Pihko, E. (2006). Immaturity of somatosensory cortical processing in human newborns. Neuroimage 33, 195-203. doi:10.1016/j.neuroimage.2006.06.041

Lin, W., Zhu, Q., Gao, W., Chen, Y., Toh, C., Gerig, G., et al. (2008). Functional connectivity MR imaging reveals cortical functional connectivity in the developing brain. AJNR Am. J. Neuroradiol. 29, 1883-1889. doi:10.3174/ajnr.A1256

Liu, W., Flax, J. F., Guise, K. G., Sukul, V., and Benasich, A. A. (2008). Functional connectivity of the sensorimotor area in naturally sleeping infants. Brain Res. 1223, 42-49. doi:10.1016/j.brainres.2008.05.054

Marin-Padilla, M. (1970). Prenatal and early postnatal ontogenesis of the human motor cortex: a Golgi study. I. The sequential development of the cortical layers. Brain Res. 23, 167-183. doi:10.1016/0006-8993(70)90038-7

Mathur, A., and Inder, T. E. (2009). Magnetic resonance imaging-insights into brain injury and outcomes in premature infants. J. Commun. Disord. 42, 248-255. doi:10.1016/j.jcomdis.2009.03.007

Mathur, A., Neil, J. J., and Inder, T. E. (2010). Understanding brain injury and neurodevelopmental disabilities in the preterm infant: the evolving role of advanced MRI. Semin. Perinatol. 34, 57-66. doi:10.1053/j.semperi.2009.10.006

Milh, M., Kaminska, A., Huon, C., Lapillonne, A., Ben-Ari, Y., and Khazipov, R. (2007). Rapid cortical oscillations and early motor activity in premature human neonate. Cereb. Cortex 17, 1582-1594. doi:10.1093/cercor/bhl069
Moody, W. J., and Bosma, M. M. (2005). Ion channel development, spontaneous activity, and activity-dependent development in nerve and muscle cells. Physiol. Rev. 85, 883-941. doi:10.1152/physrev.00017.2004

Mrzljak, L., Uylings, H., Kostovic, I., and van Eden, C. (1992). Prenatal development of neurons in the human prefrontal cortex. II. A quantitative Golgi study. J. Comp. Neurol. 316, 485-496. doi:10.1002/cne.903160408

Müller, K., Ebner, B., and Hömberg, V. (1994). Maturation of fastest afferent and efferent central and peripheral pathways: no evidence for a constancy of central conduction delays. Neurosci. Lett. 166, 9-12. doi:10.1016/0304-3940(94) 90828- 1

Müller, K., Kass-Iliyya, F., and Reitz, M. (1997). Ontogeny of ipsilateral corticospinal projections: a developmental study with transcranial magnetic stimulation. Ann. Neurol. 42, 705-711. doi:10.1002/ana.410420506

Neil, J. J., and Inder, T. E. (2004). Imaging perinatal brain injury in premature infants. Semin. Perinatol. 28, 433-443. doi:10.1053/j.semperi.2004.10.004

Nevalainen, P., Lauronen, L., Sambeth, A., Wikström, H., Okada, Y., and Pihko, E. (2008). Somatosensory evoked magnetic fields from the primary and secondary somatosensory cortices in healthy newborns. Neuroimage 40, 738-745. doi:10.1016/j.neuroimage.2007.09.075

Nevalainen, P., Pihko, E., Mäenpää, H., Valanne, L., Nummenmaa, L., and Lauronen, L. (2012a). Bilateral alterations in somatosensory cortical processing in hemiplegic cerebral palsy. Dev. Med. Child Neurol. 54, 361-367. doi:10.1111/j.14698749.2011.04165.x

Nevalainen, P., Pihko, E., Metsäranta, M., Sambeth, A., Wikström, H., Okada, Y., et al. (2012b). Evoked magnetic fields from primary and secondary somatosensory cortices: a reliable tool for assessment of cortical processing in the neonatal period. Clin. Neurophysiol. 123, 2377-2383. doi:10.1016/j.clinph.2012. 05.021

Nicholson Peterson, N., Schroeder, C. E., and Arezzo, J. C. (1995). Neural generators of early cortical somatosensory evoked potentials in the awake monkey. Electroencephalogr. Clin. Neurophysiol. 96, 599-611.

Noachtar, S., Lüders, H. O., Dinner, D. S., and Klem, G. (1997). Ipsilateral median somatosensory evoked potentials recorded from human somatosensory cortex. Electroencephalogr. Clin. Neurophysiol. 104, 189-198. doi:10.1016/S01685597(97)00013-0

Ochi, A., and Otsubo, H. (2008). Magnetoencephalography-guided epilepsy surgery for children with intractable focal epilepsy: SickKids experience. Int. J. Psychophysiol. 68, 104-110. doi:10.1016/j.ijpsycho.2007.12.008

Okada, Y., Pratt, K., Atwood, C., Mascarenas, A., Reineman, R., Nurminen, J., et al. (2006). BabySQUID: a mobile, high-resolution multichannel magnetoencephalography system for neonatal brain assessment. Rev. Sci. Instrum. 77, 024301. doi:10.1063/1.2168672

O'Leary, D. D. M., Chou, S.-J., and Sahara, S. (2007). Area patterning of the mammalian cortex. Neuron 56, 252-269. doi:10.1016/j.neuron.2007.10.010

Papadelis, C., Harini, C., Ahtam, B., Doshi, C., Grant, E., and Okada, Y. (2013). Current and emerging potential for magnetoencephalography in pediatric epilepsy. J. Pediatr. Epilepsy 2, 73-85. doi:10.3233/PEP-13040

Pierrat, V., Eken, P., and de Vries, L. (1997). The predictive value of cranial ultrasound and of somatosensory evoked potentials after nerve stimulation for adverse neurological outcome in preterm infants. Dev. Med. Child Neurol. 39, 398-403. doi:10.1111/j.1469-8749.1997.tb07453.x

Pihko, E., and Lauronen, L. (2004). Somatosensory processing in healthy newborns. Exp. Neurol. 190(Suppl. 1), S2-S7. doi:10.1016/j.expneurol.2004.01.024

Pihko, E., Lauronen, L., Wikström, H., Parkkonen, L., and Okada, Y. (2005). Somatosensory evoked magnetic fields to median nerve stimulation in newborns. Int. Congr. Ser. 1278, 211-214. doi:10.1016/j.ics.2004.11.002

Pihko, E., Lauronen, L., Wikström, H., Taulu, S., Nurminen, J., Kivitie-Kallio, S., et al. (2004). Somatosensory evoked potentials and magnetic fields elicited by tactile stimulation of the hand during active and quiet sleep in newborns. Clin. Neurophysiol. 115, 448-455. doi:10.1016/S1388-2457(03)00349-3

Pihko, E., Nangini, C., Jousmäki, V., and Hari, R. (2010). Observing touch activates human primary somatosensory cortex. Eur. J. Neurosci. 31, 1836-1843. doi:10.1111/j.1460-9568.2010.07192.x

Pihko, E., Nevalainen, P., Stephen, J., Okada, Y., and Lauronen, L. (2009). Maturation of somatosensory cortical processing from birth to adulthood revealed by magnetoencephalography. Clin. Neurophysiol. 120, 1552-1561. doi:10.1016/j.clinph. 2009.05.028 
Pihko, E., Nevalainen, P., Vaalto, S., Laaksonen, K., Mäenpää, H., Valanne, L., et al. (2014). Reactivity of sensorimotor oscillations is altered in children with hemiplegic cerebral palsy: a magnetoencephalographic study. Hum. Brain Mapp. doi: $10.1002 / \mathrm{hbm} .22462$

Pike, A., and Marlow, N. (2000). The role of cortical evoked responses in predicting neuromotor outcome in very preterm infants. Early Hum. Dev. 57, 123-135. doi:10.1016/S0378-3782(99)00061-4

Polonara, G., Fabri, M., Manzoni, T., and Salvolini, U. (1999). Localization of the first and second somatosensory areas in the human cerebral cortex with functional MR imaging. AJNR Am. J. Neuroradiol. 20, 199-205.

Rahkonen, P., Nevalainen, P., Lauronen, L., Pihko, E., Lano, A., Vanhatalo, S., et al. (2013). Cortical somatosensory processing measured by magnetoencephalography predicts neurodevelopment in extremely low-gestational-age infants. Pediatr. Res. 73, 763-771. doi:10.1038/pr.2013.46

Restuccia, D., Valeriani, M., Grassi, E., Gentili, G., Mazza, S., Tonali, P., et al. (2002). Contribution of GABAergic cortical circuitry in shaping somatosensory evoked scalp responses: specific changes after single-dose administration of tiagabine. Clin. Neurophysiol. 113, 656-671. doi:10.1016/S1388-2457(02) 00034-2

Roberts, T. P. L., Paulson, D. N., Hirschkoff, E., Pratt, K., Mascarenas, A., Miller, P., et al. (2014). Artemis 123: development of a whole-head infant and young child MEG system. Front. Hum. Neurosci. 8:99. doi:10.3389/fnhum.2014.00099

Saigal, S., and Doyle, L. W. (2008). An overview of mortality and sequelae of preterm birth from infancy to adulthood. Lancet 371, 261-269. doi:10.1016/ S0140-6736(08)60136-1

Seghier, M. L., and Hüppi, P. S. (2010). The role of functional magnetic resonance imaging in the study of brain development, injury, and recovery in the newborn. Semin. Perinatol. 34, 79-86. doi:10.1053/j.semperi.2009.10.008

Smit, B. J., Ongerboer de Visser, B. W., de Vries, L. S., Dekker, F. W., and Kok, J. H. (2000). Somatosensory evoked potentials in very preterm infants. Clin. Neurophysiol. 111, 901-908. doi:10.1016/S1388-2457(00)00245-5

Smyser, C. D., Inder, T. E., Shimony, J. S., Hill, J. E., Degnan, A. J., Snyder, A. Z., et al. (2010). Longitudinal analysis of neural network development in preterm infants. Cereb. Cortex 20, 2852-2862. doi:10.1093/cercor/bhq035

Smyser, C. D., Snyder, A. Z., and Neil, J. J. (2011). Functional connectivity MRI in infants: exploration of the functional organization of the developing brain. Neuroimage 56, 1437-1452. doi:10.1016/j.neuroimage.2011.02.073

Staudt, M., Braun, C., Gerloff, C., Erb, M., Grodd, W., and Krägeloh-Mann, I. (2006). Developing somatosensory projections bypass periventricular brain lesions. Neurology 67, 522-525. doi:10.1212/01.wnl.0000227937.49151.fd

Staudt, M., Gerloff, C., Grodd, W., Holthausen, H., Niemann, G., and KrägelohMann, I. (2004). Reorganization in congenital hemiparesis acquired at different gestational ages. Ann. Neurol. 56, 854-863. doi:10.1002/ana.20297

Staudt, M., Grodd, W., Gerloff, C., Erb, M., Stitz, J., and Krägeloh-Mann, I. (2002). Two types of ipsilateral reorganization in congenital hemiparesis: a TMS and fMRI study. Brain 125, 2222-2237. doi:10.1093/brain/awf227

Supekar, K., Musen, M., and Menon, V. (2009). Development of large-scale functional brain networks in children. PLoS Biol. 7:e1000157. doi:10.1371/journal. pbio. 1000157

Taulu, S., Simola, J., and Kajola, M. (2004). MEG recordings of DC fields using the signal space separation method (SSS). Neurol. Clin. Neurophysiol. 2004, 35.

Taylor, M. J., Boor, R., and Ekert, P. G. (1996). Preterm maturation of the somatosensory evoked potential. Electroencephalogr. Clin. Neurophysiol. 100, 448-452. doi:10.1016/S0921-884X(96)95218-2

Tesan, G., Johnson, B. W., Reid, M., Thornton, R., and Crain, S. (2010). Measurement of neuromagnetic brain function in pre-school children with custom sized MEG. J. Vis. Exp. 36, 1-4. doi:10.3791/1693

Thomas, B., Eyssen, M., Peeters, R., Molenaers, G., Van Hecke, P., De Cock, P., et al. (2005). Quantitative diffusion tensor imaging in cerebral palsy due to periventricular white matter injury. Brain 128, 2562-2577. doi:10.1093/brain/ awh600

Tovar-Spinoza, Z. S., Ochi, A., Rutka, J. T., Go, C., and Otsubo, H. (2008). The role of magnetoencephalography in epilepsy surgery. Neurosurg. Focus 25, E16. doi:10.3171/FOC/2008/25/9/E16

Vanhatalo, S., Jousmäki, V., Andersson, S., and Metsäranta, M. (2009). An easy and practical method for routine, bedside testing of somatosensory systems in extremely low birth weight infants. Pediatr. Res. 66, 710-713. doi:10.1203/PDR. 0b013e3181be9d66
Vohr, B. R., Wright, L. L., Poole, W. K., and McDonald, S. A. (2005). Neurodevelopmental outcomes of extremely low birth weight infants $<32$ weeks' gestation between 1993 and 1998. Pediatrics 116, 635-643. doi:10.1542/peds.2004-2247

Wang, C.-L., Zhang, L., Zhou, Y., Zhou, J., Yang, X.-J., Duan, S., et al. (2007). Activitydependent development of callosal projections in the somatosensory cortex. J. Neurosci. 27, 11334-11342. doi:10.1523/JNEUROSCI.3380-07.2007

Wehner, D. T., Hämäläinen, M. S., Mody, M., and Ahlfors, S. P. (2008). Head movements of children in MEG: quantification, effects on source estimation, and compensation. Neuroimage 40, 541-550. doi:10.1016/j.neuroimage.2007.12.026

White, C., and Cooke, R. W. (1994). Somatosensory evoked potentials following posterior tibial nerve stimulation predict later motor outcome. Dev. Med. Child Neurol. 36, 34-40.

Wikström, H., Huttunen, J., Korvenoja, A., Virtanen, J., Salonen, O., Aronen, H., et al. (1996). Effects of interstimulus interval on somatosensory evoked magnetic fields (SEFs): a hypothesis concerning SEF generation at the primary sensorimotor cortex. Electroencephalogr. Clin. Neurophysiol. 100, 479-487. doi:10.1016/S0921-884X(96)95688-X

Wilenius, J., Medvedovsky, M., Gaily, E., Metsähonkala, L., Mäkelä, J. P., Paetau, A., et al. (2013). Interictal MEG reveals focal cortical dysplasias: special focus on patients with no visible MRI lesions. Epilepsy Res. 105, 337-348. doi:10.1016/j.eplepsyres.2013.02.023

Wilke, M., Staudt, M., Juenger, H., Grodd, W., Braun, C., and Krägeloh-Mann, I. (2009). Somatosensory system in two types of motor reorganization in congenital hemiparesis: topography and function. Hum. Brain Mapp. 30, 776-788. doi:10.1002/hbm.20545

Willis, J., Duncan, M. C., Bell, R., Pappas, F., and Moniz, M. (1989). Somatosensory evoked potentials predict neuromotor outcome after periventricular hemorrhage. Dev. Med. Child Neurol. 31, 435-439. doi:10.1111/j.1469-8749.1989. tb04021.x

Willis, J., Seales, D., and Frazier, E. (1984). Short latency somatosensory evoked potentials in infants. Electroencephalogr. Clin. Neurophysiol. 59, 366-373. doi:10. 1016/0168-5597(84)90038-8

Woodward, L. J., Anderson, P. J., Austin, N. C., Howard, K., and Inder, T. E. (2006). Neonatal MRI to predict neurodevelopmental outcomes in preterm infants. $N$. Engl. J. Med. 355, 685-694. doi:10.1056/NEJMoa053792

Woodward, L. J., Clark, C. A. C., Bora, S., and Inder, T. E. (2012). Neonatal white matter abnormalities an important predictor of neurocognitive outcome for very preterm children. PLoS ONE 7:e51879. doi:10.1371/journal.pone.0051879

Xiang, J., Holowka, S., Sharma, R., Hunjan, A., Otsubo, H., and Chuang, S. (2003). Volumetric localization of somatosensory cortex in children using synthetic aperture magnetometry. Pediatr. Radiol. 33, 321-327. doi:10.1007/s00247-0030883-z

Yoshida, S., Oishi, K., Faria, A. V., and Mori, S. (2013). Diffusion tensor imaging of normal brain development. Pediatr. Radiol. 43, 15-27. doi:10.1007/s00247-0122496-x

Zecevic, N., Andjelkovic, A., Matthieu, J., and Tosic, M. (1998). Myelin basic protein immunoreactivity in the human embryonic CNS. Brain Res. Dev. Brain Res. 105, 97-108. doi:10.1016/S0165-3806(97)00176-4

Zhu, Y., Georgesco, M., and Cadilhac, J. (1987). Normal latency values of early cortical somatosensory evoked potentials in children. Electroencephalogr. Clin. Neurophysiol. 68, 471-474. doi:10.1016/0168-5597(87)90058-X

Conflict of Interest Statement: The authors declare that the research was conducted in the absence of any commercial or financial relationships that could be construed as a potential conflict of interest.

Received: 30 November 2013; accepted: 03 March 2014; published online: 17 March 2014.

Citation: Nevalainen P, Lauronen L and Pihko E (2014) Development of human somatosensory cortical functions - what have we learned from magnetoencephalography: a review. Front. Hum. Neurosci. 8:158. doi: 10.3389/fnhum.2014.00158

This article was submitted to the journal Frontiers in Human Neuroscience.

Copyright (C) 2014 Nevalainen, Lauronen and Pihko. This is an open-access article distributed under the terms of the Creative Commons Attribution License (CC BY). The use, distribution or reproduction in other forums is permitted, provided the original author(s) or licensor are credited and that the original publication in this journal is cited, in accordance with accepted academic practice. No use, distribution or reproduction is permitted which does not comply with these terms. 